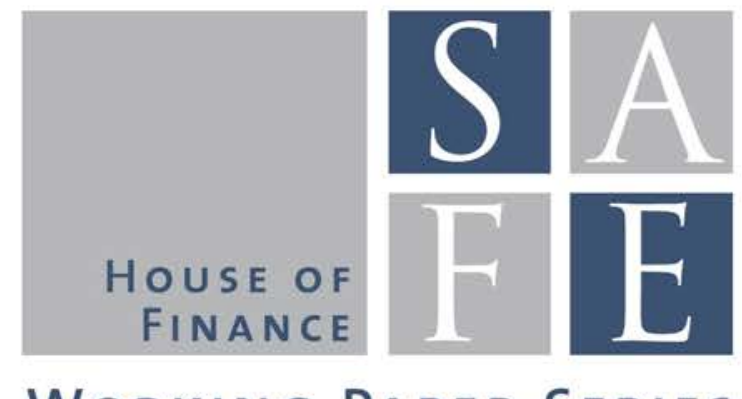

WORKINg PAPER SERIES

Michael Schneider - Fabrizio Lillo - Loriana Pelizzon

\title{
How Has Sovereign Bond Market Liquidity Changed? - An Illiquidity Spillover Analysis
}

SAFE Working Paper No. 151

SAFE I Sustainable Architecture for Finance in Europe A cooperation of the Center for Financial Studies and Goethe University Frankfurt 


\section{Non-Technical Summary}

Market liquidity, i.e. the ease of trading, is important to investors, regulators and issuers of securities in any financial market. Recent concerns are not only about illiquidity, i.e. the absence of market liquidity, but also about illiquidity risk, i.e. sudden deteriorations of liquidity. In this paper we study the transmission of illiquidity risk across different assets in the European sovereign bond market.

We focus on the Italian sovereign bond market and use a tick-by-tick dataset of all quoting and trading activity on Mercato dei Titoli di Stato (MTS) in a time-period that includes the European Sovereign Debt Crisis, the Quantitative Easing program of the ECB and the low-yield environment. We extract three different measures of liquidity based on the cost of trading and willingness of market participants to engage in trading. Based on those measures we compute a liquidity index that can be extracted for any bond at ultra-high frequency. We analyze the relationship between the liquidity indices of bonds of different maturities in two ways: i) by relating the variation in the different liquidity indices to each other and ii) by relating the intensity of sudden deteriotations in different liquidity indices.

Our main findings are that the variation of liquidity is grouped by the maturity, with very-long term 30 year bonds forming one group and medium and long term 5 and 10 year bonds forming another group, a structure that does not vary over the period we observe. With the second approach we find that spillover of illiquidity risk, i.e. the likelihood that deteriorations of liquidity spread across different bonds, is higher when the market is less liquid. During the sovereign bond crisis this spillover is strongest between bonds of similar maturity, while in 2013 illiquidity risk was strongly originating from the 10 year bonds. In the period around Quantitative Easing the 10 year bonds are less influential, but from March 2015 the very-long term bonds are both becoming more illiquid and spilling over more to other maturities.

Concluding, our paper provides a novel approach to quantify illiquidity risk and spillover of illiquidity risk that can serve as another input for policy makers when managing the bond yield curve. Targeting the weakest part of the illiquidity chain could help avoiding contagion of illiquidity and market malfunctioning. 


\title{
How Has Sovereign Bond Market Liquidity Changed? - an Illiquidity Spillover Analysis *
}

\author{
Michael Schneider ${ }^{\mathrm{a})}$, Fabrizio Lillo ${ }^{\mathrm{a})}$, and Loriana Pelizzon ${ }^{\mathrm{b})}$ \\ a) Scuola Normale Superiore, Pisa \\ b) SAFE-Goethe University Frankfurt and Ca' Foscari University of Venice
}

September 28, 2016

\begin{abstract}
Amid increasing regulation, structural changes of the market and Quantitative Easing as well as extremely low yields, concerns about the market liquidity of the Eurozone sovereign debt markets have been raised. We aim to quantify illiquidity risks, especially such related to liquidity dry-ups, and illiquidity spillover across maturities by examining the reaction to illiquidity shocks at high frequencies in two ways: a) the regular response to shocks using a variance decomposition and b) the response to shocks in the extremes by detecting illiquidity shocks and modeling those as multivariate Hawkes processes. We find that a) market liquidity is more fragile and less predictable when an asset is very illiquid and b) the response to shocks in the extremes is structurally different from the regular response. In 2015 long-term bonds are less liquid and the medium-term bonds are liquid, although we observe that in the extremes the medium-term bonds are increasingly driven by illiquidity spillover from the long-term titles.
\end{abstract}

Keywords: Liquidity, jump detection, Hawkes processes, government bonds, MTS bond market, Quantitative Easing.

*Michael Schneider and Fabrizio Lillo are at Scuola Normale Superiore, Piazza dei Cavalieri 7, 56126 Pisa, Italy. Email: michael.schneider@sns.it and fabrizio.lillo@sns.it respectively. Loriana Pelizzon is at Goethe University Frankfurt - Faculty of Economics and Business Administration and Research Center SAFE, Theodor-W.-Adorno-Platz 3, D-60323 Frankfurt am Main, Germany, and Ca Foscari University of Venice, Dorsoduro 3246, Venice, Veneto 30123, Italy. Email: pelizzon@safe.uni-frankfurt.de and loriana.pelizzon@unive.it. Loriana Pelizzon thanks the Research Center SAFE, funded by the State of Hessen Initiative for Research (LOEWE), for the financial support. We thank Mario Bellia, Enrico Melchioni, Davide Tomio, Jun Uno and participants at the XVII Workshop on Quantitative Finance, Pisa, the Workshop on Sovereign Bonds and Quantitative Easing, Frankfurt, the 4th PhD Workshop in Economics, Braga, and the 2nd SAFE Market Microstructure Workshop, Frankfurt, for helpful comments. We also thank the MTS group for providing us with access to their datasets. The views expressed in the paper are solely those of the authors. We are responsible for all remaining errors. 


\section{Introduction}

Market liquidity - the ability to quickly trade large quantities of an asset at a low cost - is crucial to the functioning of financial markets and therefore of great interest to both market participants and policymakers. Illiquidity - the absence of market liquidity - is a threat to investors who rely on accurate quotes and the possibility to transform their liquid assets into cash, to issuers who see demand wane if their assets turn illiquid and to regulators who are concerned about the functioning of markets. Ultimately illiquidity also impedes the efficient allocation of capital and thus hinders economic growth.

It is therefore concerning that market liquidity has recently come to be seen as deteriorating in many markets. In his annual letter to shareholders JPMorgan Chase \& Co CEO Jamie Dimon" warns that "liquidity has gotten worse and we have seen extreme volatility and distortions in several markets" and "we really need to be prepared for the effects of illiquidity when we have bad markets." As reasons he lists, among others, that there are fewer market makers which hold less inventory, regulation, structural issues such as high-frequency trading and that only smaller trade sizes are available.

Adding to the points made by Jamie Dimon, over the last five years the Eurozone went through the sovereign debt crisis and is currently impacted by the Quantitative Easing program of the European Central Bank (ECB) and an environment of low or even negative bond yields. Regulatory constraints are increasing. The proposed EU banking structural reform ${ }^{2}$ and the separation of proprietary trading of banks enshrined therein will likely drive more participants out of the market and lead to a further reduction in liquidity.

Therefore there is good reason to scrutinize the market liquidity of the secondary market for European sovereign bonds under these aspects. The best data on the secondary market comes from Mercato dei Titoli di Stato (MTS), the largest interdealer platform for European sovereign bonds. We use their dataset to study market liquidity, its reaction and resilience to liquidity shocks as well as spillover of illiquidity at ultra-high frequency. We focus our analysis on Italy because of the reliability of the data and the elevated importance of the Italian market to the Eurozone and look to the 5, 10 and 30 year titles.

One of the most straightforward measures of liquidity is bid-ask spread, i.e. the price difference between the lowest ask quote and the highest bid offer. Taking into account only bid-ask spread, the secondary market for Eurozone government debt appears healthy for medium- and long-term bonds, with spreads for 5 and 10 year titles low and stable and only very long-term 30 year bonds exhibiting higher spreads, at least partially contradicting the concerns voiced above. We are however going to make a case that it is necessary to look to several measures of liquidity as bid-ask spread alone can drastically overestimate liquidity and underestimate liquidity risk. This is because bid-ask spread can be strongly distorted by a single quote of potentially only small size when investors seek larger volumes. We therefore include metrics of spread, price impact and depth across the limit order book when

\footnotetext{
${ }^{1}$ Jamie Dimon, annual letter to shareholders of JPMorgan Chase \& Co., April 2016. Available at https://www.jpmorganchase.com/corporate/investor-relations/document/ ar2015-ceolettershareholders.pdf

${ }^{2}$ See http://www. consilium. europa.eu/en/policies/banking-structural-reform/
} 
measuring liquidity.

Furthermore concerns are not so much about the level of liquidity but rather illiquidity risk and anxiety about the situation in "bad markets". Amid such concerns about regulatory and structural changes as well as about flash events Adrian et al. study the market liquidity of on-the-run U.S. treasuries in their blog post "Has U.S. Treasury Market Liquidity Deteriorated?"3 Using spread as well as depth, price impact and other liquidity measures, the evidence they find "is fairly favorable about the current state of Treasury market liquidity." However they conclude that "perhaps the concerns are not so much about average liquidity levels, as we examined, but about liquidity risk. Indeed the events of October 15 and similar episodes of sharp, seemingly unexplained price changes in the dollar-euro and German Bund markets have heightened worry about tail events in which liquidity suddenly evaporates."

In our analysis we address exactly this concern about illiquidity risks and bad markets. Specifically "dry-ups" of liquidity are a major threat to the functioning of financial markets. In a liquidity dry-up of a financial market that is organized as a limit order book, the book thins out and eventually all standing quotes are suspended or canceled, leaving an empty book where it is impossible to trade. ${ }^{4}$ We also address the problem of illiquidity spillover, i.e. the reaction of liquidity to illiquidity shocks in other assets. If this reaction is sufficiently strong, contagion effects, where illiquidity spreads across assets, become a risk to the functioning of the market and can impede diversification effects.

We aim to quantify illiquidity risks and the risk of liquidity dry-ups in two ways: First we investigate the dynamics in response to a shock under regular conditions using a VAR model estimated at one-minute frequency, and apply a generalized variance decomposition to quantify the variation caused by shocks in the same and in different assets. We are not aware of any other paper that uses the generalized variance decomposition on liquidity across assets. ${ }^{5}$

Second to study fragility of market liquidity in extreme events ("in the tail") we develop a novel approach where we identify rapid deteriorations of liquidity directly at very short time scales and model these events using multivariate Hawkes processes. From the estimated model parameters we can compute the fraction of events that are caused by self-excitation from events in the same asset and cross-excitation from other assets. The higher the fraction of self-excited events, the more likely an initial liquidity shock to the asset is amplified by exciting further liquidity shocks. i.e. the asset is prone to illiquidity cascades that can lead to a dry-up of liquidity and thus more fragile and less resilient. The fraction of cross-excited events instead quantifies spillover of illiquidity between different bonds and serves as an indicator of the lead-lag structure in the arrival of illiquidity shocks between bonds of different maturities. The advantage of this approach is that by the definition of the events we are observing the tail of the distribution of liquidity changes and, unlike

\footnotetext{
${ }^{3}$ Adrian T., M. Fleming, D. Stackman and E. Vogt (2015), "Has U.S. Treasury Market Liquidity Deteriorated?", available at http://libertystreeteconomics.newyorkfed.org/2015/08/ has-us-treasury-market-liquidity-deteriorated.html

${ }^{4}$ Liquidity dry-up also refers to the situation when it becomes impossible for an institution to obtain funding liquidity. While ultimately both cases are related (Brunnermeier and Pedersen (2009)), in this paper we focus on the case of the breakdown of the limit order book.

${ }^{5}$ Similar to how Diebold and Yilmaz (2014) study the variance decomposition of volatility across assets.
} 
with e.g. correlation, are able to give a directionality to illiquidity spillover.

The regular dynamics reveals a band structure, stable over time, where 5 year and 10 year bonds group together, distinguished from the very-long term 30 year bonds and that commonality of liquidity at high-frequencies mainly arises through the correlated arrival of liquidity shocks.

For the extreme event analysis we find that fragility to such shocks coincides with illiquidity, i.e. the market is more fragile to illiquidity shocks in periods when it is less liquid. Across assets of different maturities we do not observe a band structure as for the regular dynamics but rather a more complex connectedness that is changing over time and increasing in intensity from 2011 to 2015. While during the sovereign bond crisis in 2011 illiquidity spillover was block-diagonal, i.e. strongest between bonds of similar maturities, in 2013 the 10 year titles held a sort of benchmark status for illiquidity, with illiquidity spilling over more from the 10 year to the 5 and 30 year titles than the other way round. In 2015 instead the 10 year titles loose this leading role and we observe that from March, at the same time when the implementation of Quantitative Easing commenced, the 30 year titles are increasingly driving illiquidity in the 10 year bonds.

So how has sovereign bond markets liquidity changed? Liquidity is quite good in medium- and long-term 5 and 10 year bonds. However the very long-term 30 year titles have dried up. This is worrisome given that we also observe the same 30 year bonds to become a driver of illiquidity spillover in bonds of lower maturity. Hence illiquidity risk in medium- and long-term could be much greater than it seems on the surface.

The rest of the paper proceeds as follows. Section 2 reviews the related literature and highlights our contribution. Section 3 describes the structure of the European sovereign bond market, our data set and the context of the European sovereign bond crisis and Quantitative Easing. In Section 4 we define the underlying liquidity measures we use and provide descriptive statistics. Section 5 analyzes the dynamics of the mean of liquidity and we use these to motivate the discussion of the dynamics in the tail of the distribution of liquidity in Section 6. In Section 6 we define illiquidity events and estimate a Hawkes model of their intensity process. We then apply this approach to our data set and give an interpretation of the results as a new measure of resilience of liquidity and illiquidity spillover. Section 7 concludes.

\section{Related Literature}

Our work is related and contributes to various strands of literature on bond markets and their liquidity, on commonality in liquidity and on Hawkes processes and jump detection.

Regarding bond markets and bond market liquidity there is a vast literature that focuses on the US bond market, given its size and the availability of data bases such as TRACE. Chakravarty and Sarkar (1999) study the determinants of the realized bid-ask spread in the U.S. corporate, municipal and government bond markets for the years 1995 to 1997. Goyenko et al. (2011) compare the liquidity and its determinants of on- and off-the-run treasuries of different maturities. They find evidence of a flight-to-quality to more liquid short-term bonds during recessions and that off-the-run liquidity is better forecasted by macro variables. For example 
Dick-Nielsen et al. (2012) study the impact of market liquidity on corporate bond yield spreads in the context of the US subprime crisis based on quarterly data or Friewald et al. (2012) use a set of more than 20,000 corporate bonds and several liquidity measures, finding that liquidity effects are more pronounced in periods of crisis.

Fleming and Remolona (1999) study the price and volume response of US Treasury markets to unanticipated news and Pasquariello and Vega (2007) use a parsimoneous trading model to show that order flow and yield changes are linked to macro news. Engle et al. (2012) (based on prior work by Engle (2002)) propose a new LOB model to analyze volatility and liquidity in the context of economic announcements and the financial crisis period.

Pasquariello and Vega (2012) study the impact of open market operations (POMOs) by New York FED and find a positive impact on market liquidity. Fleming (2003) uses high-frequency data to compare different liquidity metrics in the US Treasuries market and finds that the bid-ask spread is particularly useful.

For the European bond market most studies rely on data provided by MTS. A notable exception is Linciano et al. (2014) that compares the liquidity of corporate bonds across three retail platforms. ${ }^{6}$ Dufour et al. (2004) give a description of the MTS data set and Cheung et al. (2005) study the microstructure and market order flow of MTS using trade-to-trade data from January 2001 to May 2002 and find that the domestic and EuroMTS platforms, despite their technical fragmentation, are closely connected in terms of liquidity. Caporale and Girardi (2011) confirm this and find that EuroMTS contributes ca. $20 \%$ to price discovery using daily data from January 2004 to March 2006. In Caporale and Girardi (2013) they extend this work on price discovery in the light of the restructuring of the regulatory framework. Dunne et al. (2010) use trade data of the last three quarters of 2005 from the Request-for-Quote platform Bondvision to compare the B2B (interdealer) segment (MTS) with the B2C (retail) segment (BondVision). ${ }^{7}$ Coluzzi et al. (2008) study the liquidity of the Italian secondary market on intraday data from MTS for the years 2004 to 2006, at different frequencies and comparing a variety of liquidity measures. They find that there is no clear relationship between trading and LOB measures.

Dufour and Nguyen (2012) study the permanent price impact of trades, which they find to be priced as a function of market uncertainty, using data from April 2003 to September 2007 sampled at 10 second intervals. Beber et al. (2009), using data from April 2003 to December 2004, finds that while yield spread differences are explained by credit quality, flows into the bond market are chasing liquidity rather than credit quality.

A considerable number of articles is placed in the context of the European sovereign bond crisis: Darbha and Dufour (2013b) review the microstructure of the Euro area government bond market and MTS, comparing also to the US market. They review liquidity measures with a focus on the bond market, study determinants of liquidity before and after the onset of the sovereign bond crisis using

\footnotetext{
${ }^{6}$ Beber and Pagano (2008) study liquidity on one of these platforms, TLX, and discuss this possible extension.

${ }^{7}$ Dunne et al. (2006) and Dunne et al. (2006) are also related with a focus on trade-transparancy. BondVision is part of the MTS Group.
} 
aggregated monthly data from January 2004 to July 2010 and show the presence of a term structure in spread. Bai et al. (2012) use data up to May 2012 to conclude that the Eurozone sovereign bond crisis is largely driven by credit risk after late 2009 and not, as initially, by liquidity risk. Along a similar line Darbha and Dufour (2013a) consider the contribution of liquidity to yield spreads and find that it becomes an important explanatory factor to yield dynamics after the crisis and to yield spreads before and after the crisis. Pelizzon et al. (2015) use data from June 2011 to December 2012 to study the relationship between market liquidity and credit risk at a daily scale. They find a significant relationship where credit risk leads liquidity which is enhanced when the CDS spread is above the $500 \mathrm{bp}$ threshold but relaxed after the LTRO program of ECB.

Second our study relates to the literature on commonality in liquidity. Chordia et al. (2000) introduce commonality in liquidity and correlated movements in liquidity for equities to the market microstructure literature. ${ }^{8}$ Brunnermeier and Pedersen (2009) develop a theoretical model that links assets' liquidity to the supply side, i.e. traders' funding liquidity, explaining not only commonality in liquidity but also liquidity dry-ups and the relation to volatility. Empirical evidence for this comes from Coughenour and Saad (2004) that incorporate information of the market-making NYSE specialist into the model of Chordia et al. (2000). Kamara et al. (2008) and Koch et al. (2009) instead provide evidence of increased commonality in liquidity through institutional/mutual funds ownership, i.e. the demand side. Karolyi et al. (2012) make use of differences in the regulatory framework in 40 countries to disentangle the demand- and supply side sources of commonality in liquidity and find demand-side forces being more influential. Hameed et al. (2010) show that stock market declines increase the commonality in liquidity. Brockman et al. (2009) extend the idea from commonality within markets to commonality across global stock markets. Lee (2011) argues that both global and local liquidity risk is priced, depending on the properties of a country's market. Commonality in liquidity has been studied also for other markets: Marshall et al. (2013) document liquidity commonality in commodity futures markets and find no consistent link to stock market liquidity; Mancini et al. (2013) and Banti et al. (2012) find evidence of strong commonality in liquidity and that liquidity risk is priced in the FX market and Chordia et al. (2005) analyze volatility and liquidity co-movements in the stock and bond markets. For the bond market Fleming (2003) finds high correlation of liquidity across US Treasuries and concludes that the liquidity of one security can serve as a reasonable proxy for the market as a whole. In the European case Coluzzi et al. (2008) document commonality in liquidity between Italian on-the-run securities of different maturities.

Furthermore our study is closely linked to the literature on Hawkes processes and jump detection. It is now established that modeling financial returns requires a diffusion and a jump component, with important implications for derivatives pricing, portfolio selection or risk management (Aït-Sahalia (2004)). While our work is not directly related to jump detection, let us point out that several methods have been proposed to detect jumps or the presence of jumps, based on high-frequency returns data, and have been reviewed e.g. in Dumitru and Urga (2012). ${ }^{9}$ Other

\footnotetext{
${ }^{8}$ See also Hasbrouck and Seppi (2001) and Huberman and Halka (2001).

${ }^{9}$ Similar studies are Theodosiou and Zikes (2011) and Schwert (2009).
} 
articles have aimed to detect price jumps in the context of economic events, e.g. Almgren (2012) uses exponential averaging to identify scheduled events that are economically significant for Eurex interest rate products. ${ }^{10}$ Hawkes processes are a class of self-exciting processes introduced by Hawkes (1971a) and Hawkes (1971b) and initially applied to model earthquake data (Vere-Jones (1970), Ogata (1988), Vere-Jones (1995)).

They are now widely used in Economics and Finance to describe dis-continuous processes, often identified as jumps, beyond the jump component of returns. For a recent review of applications in Finance see Bacry et al. (2015). In Economics e.g. Aït-Sahalia et al. (2014) model credit default intensities as multi-dimensional Hawkes processes and derive a link to CDS prices to study the impact of shocks in the European sovereign CDS market. Aït-Sahalia et al. (2015) use a momentbased estimation method to capture self- and cross-excitation in the dynamics of worldwide index returns. In an approach that is somewhat similar to ours, Bormetti et al. (2015) identify the intraday times of price jumps from data sampled at oneminute intervals to estimate systemic price cojumps with a Hawkes factor model.

Our contribution is to consider, beyond the dynamics in the mean of the distribution of liquidity, the dynamics in the tail. First we document commonality in liquidity across bonds at high intraday frequencies as opposed to daily or weekly measures and apply the generalized variance decomposition to liquidity. Second we focus on the tail of the liquidity distribution. By modeling illiquidity shocks as a self- and cross-exciting process we introduce the notion of resilience of liquidity to illiquidity shocks and illiquidity spillover or commonality of liquidity in the tails. Third we are among the first to consider the impact of Quantitative Easing in the Eurozone on the liquidity of the sovereign bond market.

\section{Data and Market Structure}

\subsection{Structure of the European Sovereign Bond Market}

The sovereign bond market of the Eurozone is one of the largest in the world with $€ 6.8$ trillion outstanding nominal value at the end of 2015 . $^{11}$ The secondary market for European sovereign bonds is divided into an opaque over-the-counter market and an observable exchange-traded market. The market share of both markets depends on the issuing country and is not always (publicly) known.

The exchange-traded market is further divided into dealer-to-dealer and dealerto-customer platforms and different trading mechanisms of the platforms (e.g. request for quote (RFQ), limit order book (LOB)) and some of these platforms exist only for titles of specific European countries. Of these platforms Mercato dei Titoli di Stato (MTS) is the leading interdealer trading platform for European sovereign bonds. ${ }^{12}$ It is organized as an electronic limit order book and minimum quote and transaction sizes are typically $€ 1$ million or larger.

\footnotetext{
${ }^{10}$ Both Johnson et al. (2013) and Golub et al. (2012) algorithmically define crash events in the context of flash crashes.

${ }^{11}$ Nominal Value of outstanding amounts issued by central governments according to ECB: https://www.ecb.europa.eu/stats/money/securities/debt/html/index.en.html

${ }^{12}$ See Pelizzon et al. (2015) and Dufour et al. (2004)
} 
In our empirical analysis we will focus on the Italian sovereign bond market for four reasons. First for its size, since Italy is one of the biggest debtors in the European Union with $€ 1.8$ trillion government debt outstanding as of the end of 2014. ${ }^{13}$ Beyond its size the Italian market is of even bigger importance as a pillar of the Euro. During and after the crisis, Italy was repeatedly seen as crucial to the survival of the Eurozone. ${ }^{14}$ Third, as we are studying dry-ups of market liquidity we prefer to do so on a sample where dry-ups occur and thus are more than just a theoretical risk, as is the case here. Lastly, we place special trust in the data available. While the MTS dataset comprises all European national markets, the Italian market stands out as especially liquid. Furthermore we have access to information that allows us to quantify the market share of MTS and ensure our data is representative.

Besides historical reasons the role of MTS in the Italian market is elevated in that it is used by the Italian treasury to evaluate the performance of primary market participants in terms of liquidity provision. ${ }^{15}$ Its market share in 2014 was $45.4 \%$ of trading in organized platforms and $18.6 \%$ of all trading activities (including OTC) reported to the Italian securites and exchange commission CONSOB. ${ }^{16}$ Given the historical evolution of these figures we are confident to use MTS as a proxy both for the regulated and the OTC market. Our sample is therefore also an example of a dominant exchange market functioning in parallel to an over-the-counter market.

\subsection{Data Set}

Our dataset ${ }^{17}$ contains all trades and quotes (named "proposals") ${ }^{18}$ on the MTS platform from June 2011 to December 2015 at millisecond or higher resolution. ${ }^{19}$ The information on trades contains both the requested and executed volume, information on quotes includes an identifier enabling us to track participants throughout the day. ${ }^{20}$ From the set of proposals we construct the full limit order book (LOB) at the same resolution of the raw data.

For our empirical analysis we restrict our dataset to three subperiods. The first subperiod is from June 2011 through February 2012 and contains the "core" of the sovereign bond crisis. The second subperiod is from March 2013 through December 2013 and was comparatively calm. The third subperiod lasts from October 2014 through June 2015 which includes the period leading up to the announcement of Quantitative Easing in the Eurozone until the first months of its implementation. Our motivation for choosing these periods is to span a large period of time over our dataset, to include both troubled (sovereign bond crisis) and (relatively) calm

\footnotetext{
${ }^{13}$ http://www.dt.tesoro.it/en/debito_pubblico/_link_rapidi/debito_pubblico.html

${ }^{14}$ See e.g. http://www.ft.com/cms/s/0/1ef8289c-baef-11e1-b445-00144feabdc0.html

${ }^{15}$ See http://www.dt.tesoro.it/en/debito_pubblico/specialisti_titoli_stato/

${ }^{16}$ CONSOB, Bollettino Statistico Nr. 8, March 2016, available at http://www. consob.it/web/ area-pubblica/bollettino-statistico

${ }^{17}$ See also Pelizzon et al. (2015) and Dufour et al. (2004)

${ }^{18}$ Quotes are binding and thus correspond to limit orders.

${ }^{19}$ From the beginning of 2013 the data has microsecond resolution.

${ }^{20}$ I.e. each proposal has a unique identifier per bond and day. As changes to a proposal usually happen as updates to the proposal instead of cancellation and re-issue of a new proposal we are able to track single participants throughout the day.
} 
times (2013) and especially to include the Quantitative Easing period to analyze the resulting effects.

Along the bond dimension we include the three most recently issued 5, 10 and 30 year fixed-rate Italian government bonds (Buoni del Tesoro Poliennale, BTP) that are actively traded during the whole subperiod, making for a total of nine bonds per period. ${ }^{21}$ By focusing on these three maturity bins we capture relatively short-term 5 year bonds that are highly affected by close to zero yields towards the end of our sample in 2015, the 10 year BTP which is widely used as a benchmark and the very long-term 30 year bonds which are an indispensable asset to many institutional investors. In the U.S. treasury market the on-the-run, i.e. the most recently issued bond of a maturity, enjoys special status and better liquidity than older off-the-run bonds. This is not the case in Europe ${ }^{22}$ and performing our analysis on three bonds per maturity improves our statistics without dispersing too much over different times to maturity. The list of ISINs is given in Appendix A.

\subsection{Timeline}

The period that we are considering is characterized by financial distress in the Eurozone and both fiscal measures of the European Union and various interventions by the ECB were aimed to contain the effects of the crisis.

The European sovereign debt crisis started in 2009 when concerns surfaced that peripheral Eurozone member states, especially Greece, would not be able to repay their debt. Greece was first bailed out in May 2010 and the simultaneous creation of the European Financial Stability Facility (EFSF) ${ }^{23}$ by the EU was aimed to contain the crisis. At the same time the Securities Market Program (SMP) by the ECB conducted "interventions in the euro area public and private debt securities markets to ensure depth and liquidity in those segments which are dysfunctional" with the objective to "address the malfunctioning of securities markets and restore an appropriate monetary policy transmission mechanism". ${ }^{24}$ In November 2010 Ireland and in May 2011 Portugal required help from the EFSF and by August 2011 fear of a further contagion let Spanish and Italian 10 year bond yields breach $6 \%$ and led the ECB to reactivate the SMP to purchase mostly Spanish and Italian sovereign debt during the same month. ${ }^{25}$ Subsequent rating downgrades and international concerns mounted pressure on the Italian government under Berlusconi that was replaced by a technocratic cabinet in November 2011. In December 2011

\footnotetext{
${ }^{21}$ Thus our subsample includes the on-the-run bond of each maturity bin at least on the first day of the subperiod, however if a new on-the-run is issued during the subperiod it is not included to ensure consistency of the normalization of the PCA measure (see below).

${ }^{22}$ Coluzzi et al. (2008), see also Section 4.2 .

${ }^{23}$ A special investment vehicle that could provide funding to Eurozone states in financial difficulties with a volume of up to $€ 440$ billion. Official press release available at http: //www . consilium . europa.eu/uedocs/cms_data/docs/pressdata/en/ecofin/114324.pdf. Volume enlarged to $€ 780$ billion in July 2011, see http://www.efsf .europa.eu/attachments/faq_en.pdf

${ }^{24}$ Official press release available at http://www.ecb.europa.eu/press/pr/date/2010/html/ pr100510.en.html. See also Ghysels et al. (2014)

${ }^{25}$ See Ghysels et al. (2014) and press release http://www.ecb.europa.eu/press/pr/date/ 2011/html/pr110807.en.html. The total amount of Italian debt purchased in both rounds of the SMP amounts to over $€ 100$ billion, see http://www.ecb.europa.eu/press/pr/date/2013/ html/pr130221_1.en.html.
} 
and February 2012 the ECB used their Long Term Refinancing Operation (LTRO) to infuse credit into the banking system at exceptionally good conditions, which indirectly lowered yields (Crosignani et al. (2015)). Spain required assistance from the EFSF in June 2012 but, in the light of significantly lowered interest rates and the "whatever it takes" speech of ECB president Draghi in July 2012, the situation subsequently relaxed by mid 2012 to early 2013.

After cutting the deposit interest rate to negative terrain in June 2014, on 22 January 2015 the ECB announced their Quantitative Easing (QE) program under the name of Public Sector Purchase Program (PSPP) to stimulate the economy in order to avoid deflation. The PSPP was started in March 2015 with a monthly volume of $€ 50$ billion of purchases of euro area sovereign debt ${ }^{26}$ adding to purchase programs of monthly $€ 10$ billion for asset backed securities and covered bonds in place since October 2014. In the QE program the ECB is targeting bonds with a remaining maturity of 2-30 years, trying to be as market-neutral as possible. ${ }^{27}$ For Italy this translates to monthly purchases of sovereign bonds of $€ 7.7$ billion.

\section{Liquidity}

\subsection{Liquidity Measures}

In general trades on the MTS are rare and trade-based measures of liquidity ${ }^{28}$ can only be sensibly defined at daily or lower frequencies. Also, as reported by Coluzzi et al. (2008), the relationship between limit order book- and trade-based measures of liquidity is not as clear on MTS. Since we are interested in the dynamics of liquidity at high frequencies and willingness to trade, we observe liquidity via the limit order book of executable quotes.

Given that we often observe situations were e.g. the bid-ask spread is determined by a single set of quotes on the bid and ask side that are significantly removed from the price levels were liquidity is concentrated and therefore no longer representative of market liquidity, we do not base our analysis on one liquidity metric alone. ${ }^{29}$ Notably such situations arise especially frequently when the market is illiquid, making a more complementary approach even more necessary. Therefore we compute three "raw" metrics of liquidity from the limit order book that correspond to different facets of liquidity, and then compute a condensed measure of liquidity based on their principal component. Following the approach of Pelizzon et al. (2014) we use the following three "raw" measures of liquidity:

- (Bid-Ask) Spread is defined as the best ask minus the best bid price and captures the (round-trip) cost of small trades.

\footnotetext{
${ }^{26} 12 \%$ of which for debt issued by European institutions

27 "The intention is to be market-neutral. The Eurosystem wants to create as little distortion as possible. At the same time, this will not be a strict target and flexibility will be applied, also taking into account the relative values of bonds and the liquidity of the different maturity segments." from https://www. ecb. europa.eu/mopo/implement/omt/html/pspp-qa.en.html. For a summary see e.g. Claeys et al. (2015)

${ }^{28}$ Compare e.g. Goyenko et al. (2009)

${ }^{29}$ See also the discussion in Section 6 and Appendix E.1 for an example where bid-ask spread is misleading as an indicator of market liquidity.
} 
- Inverse Depth on the ask (bid) side is defined as how much a buy (sell) trade of size $€ 15$ million would shift the best ask (bid) price at any instant of time. ${ }^{30}$ To obtain inverse depth we take the mean of the measures on the bid and ask side. Inverse depth, in the absence of frequent trades, is a measure of (the virtual or mechanical) price impact. ${ }^{31}$

- Total (Quoted) Volume is the sum of all the volume quoted in the limit order book, irrespective of price. As for inverse depth we take the mean of the bid and ask sides. It is highly correlated $(>95 \%)$ with the number of active proposals and indicates general willingness to participate in the market and depth of the whole book.

To obtain a condensed measure of illiquidity we perform a principal component analysis (PCA) for each bond as in Mancini et al. (2013) and Fleming (2003).

The eigenvector corresponding to the first principal component, capturing the majority of variance in liquidity, has positive eigenvector loadings in the spread and inverse depth component and negative loading in the total volume component, thus measuring illiquidity. We construct the time-series of our condensed illiquidity measure PCA1 at the same time-resolution as our data. ${ }^{32}$

\subsection{Liquidity Statistics}

Table 1 presents the summary statistics for the underlying liquidity measures defined in the previous section, distinguished by bond and subperiod. Let us first comment on the term structure of liquidity. As Darbha and Dufour (2013b) we find a term structure of liquidity where medium-term 5 year BTPs are more liquid than long-term 10 year titles which themselves are more liquid than the very long-term 30 year bonds. We do not find systematic differences between the more or less recently issued bonds of the maturity bins, which is in agreement with previous literature that does not find an effect from on-the-run status ${ }^{33}$ on MTS as is the case for US bonds (Coluzzi et al. (2008)). The table also reveals huge differences in the levels of liquidity between the periods we consider. During the sovereign bond crisis in 2011/12 the average spread was ca. 50 basis points, comparing to ca. 10 basis points in 2013 and ca. 12 basis points in 2014/15 for the 10 year BTPs. This holds similarly for inverse depth where the mean was around 4 basis points during the sovereign bond crisis, falling to less than 1 basis point in 2013 and slightly larger than 1 basis point around the onset of QE. The average values of total quoted volume instead do not differ much between 2011/12 and 2013, they are around $€ 140$ million for the 5 year BTPs and slightly more than $€ 130$ million for the 10 year

\footnotetext{
${ }^{30}$ The amount of $€ 15$ million was chosen as the $90 \%$ percentile of trade sizes. Inverse depth thus reflects the cost of a large trade requiring immediacy (Pelizzon et al. (2014)).

${ }^{31}$ While price impact is typically computed as a regression of price changes on order flow, having at our disposition the complete limit order book we can also compute the mechanical price response that would arise to a given trade. This virtual or mechanical price impact is however only one component of price impact, as the reaction of market participants to trades also plays a role, which can not be captured in this way.

${ }^{32}$ I.e. PCA1 can be computed at every update of the limit order book, at millisecond- or higher resolution. The details of computing PCA1 are described in Appendix B.

${ }^{33}$ The most recently issued bond of a maturity bin is called the "on-the-run".
} 


\begin{tabular}{|c|c|c|c|c|c|c|c|c|c|c|c|}
\hline & \multicolumn{3}{|c|}{5 year BTP } & \multicolumn{3}{|c|}{10 year BTP } & \multicolumn{3}{|c|}{30 year BTP } \\
\hline & & & 3 & 2 & 1 & 3 & 2 & 1 & 3 & 2 & 1 \\
\hline \multirow{12}{*}{$2011 / 12$} & \multirow{4}{*}{$\begin{array}{l}\text { Spread } \\
\text { (in bp) }\end{array}$} & $10 \% \mathrm{Q}$ & 16.0 & 15.0 & 12.0 & 20.0 & 20.0 & 11.0 & 38.0 & 42.0 & 33.0 \\
\hline & & mean & 47.8 & 46.0 & 42.9 & 68.9 & 64.6 & 48.8 & 118.4 & 146.5 & 120.1 \\
\hline & & median & 33.0 & 33.0 & 30.0 & 50.0 & 47.0 & 37.0 & 94.0 & 112.0 & 94.0 \\
\hline & & $90 \% \mathrm{Q}$ & 99.0 & 91.0 & 88.0 & 125.0 & 120.0 & 97.0 & 200.0 & 238.0 & 203.0 \\
\hline & \multirow{4}{*}{$\begin{array}{l}\text { Inverse } \\
\text { Depth (in } \\
\text { bp) }\end{array}$} & $10 \% \mathrm{Q}$ & 0.5 & 0.5 & 0.5 & 0.5 & 0.5 & 0.5 & 1.0 & 1.0 & 1.0 \\
\hline & & mean & 2.7 & 2.9 & 3.2 & 4.1 & 3.8 & 4.5 & 7.1 & 5.6 & 5.8 \\
\hline & & median & 1.5 & 1.5 & 1.5 & 2.0 & 1.5 & 2.0 & 3.0 & 2.5 & 3.0 \\
\hline & & $90 \% \mathrm{Q}$ & 5.0 & 5.0 & 5.5 & 6.0 & 6.0 & 7.5 & 9.0 & 8.0 & 9.5 \\
\hline & Total & $10 \% \mathrm{Q}$ & 102.5 & 108.0 & 103.0 & 88.8 & 92.0 & 92.0 & 67.5 & 67.5 & 69.0 \\
\hline & Quoted & mean & 144.6 & 151.3 & 144.8 & 130.2 & 134.9 & 133.9 & 90.0 & 89.9 & 92.1 \\
\hline & Volume & median & 142.8 & 153.8 & 146.5 & 131.8 & 137.2 & 136.5 & 91.8 & 92.5 & 94.5 \\
\hline & (in $€ \mathrm{em})$ & $90 \% \mathrm{Q}$ & 194.5 & 192.0 & 187.5 & 171.5 & 174.8 & 172.0 & 112.0 & 110.5 & 114.2 \\
\hline \multirow{12}{*}{2013} & \multirow{4}{*}{$\begin{array}{l}\text { Spread } \\
\text { (in bp) }\end{array}$} & $10 \% \mathrm{Q}$ & 5.0 & 5.0 & 5.0 & 7.0 & 6.0 & 7.0 & 15.0 & 17.0 & 16.0 \\
\hline & & mean & 8.4 & 8.5 & 8.3 & 10.3 & 9.1 & 10.4 & 23.4 & 24.9 & 23.9 \\
\hline & & median & 8.0 & 8.0 & 8.0 & 10.0 & 9.0 & 10.0 & 22.0 & 24.0 & 23.0 \\
\hline & & $90 \% \mathrm{Q}$ & 12.0 & 12.0 & 12.0 & 14.0 & 12.0 & 15.0 & 30.0 & 31.0 & 30.0 \\
\hline & \multirow{4}{*}{$\begin{array}{l}\text { Inverse } \\
\text { Depth (in } \\
\text { bp) }\end{array}$} & $10 \% \mathrm{Q}$ & 0.0 & 0.0 & 0.0 & 0.0 & 0.0 & 0.0 & 0.5 & 0.5 & 0.5 \\
\hline & & mean & 0.5 & 0.5 & 0.6 & 0.7 & 0.9 & 0.9 & 1.5 & 1.5 & 1.4 \\
\hline & & median & 0.5 & 0.5 & 0.5 & 0.5 & 0.5 & 0.5 & 1.0 & 1.0 & 1.0 \\
\hline & & $90 \% \mathrm{Q}$ & 1.0 & 1.0 & 1.5 & 1.5 & 1.5 & 2.0 & 3.0 & 2.5 & 2.5 \\
\hline & Total & $10 \% \mathrm{Q}$ & 118.0 & 113.0 & 115.5 & 114.5 & 114.0 & 111.5 & 88.5 & 90.5 & 90.2 \\
\hline & Quoted & mean & 142.5 & 137.8 & 139.4 & 135.7 & 135.8 & 133.7 & 106.1 & 107.8 & 108.2 \\
\hline & Volume & median & 146.0 & 140.2 & 142.5 & 139.0 & 139.2 & 136.5 & 109.0 & 110.5 & 110.5 \\
\hline & (in $€ \mathrm{em})$ & $90 \% \mathrm{Q}$ & 164.0 & 160.5 & 160.5 & 154.2 & 154.5 & 153.5 & 121.5 & 122.5 & 124.5 \\
\hline \multirow{12}{*}{$2014 / 15$} & \multirow{4}{*}{$\begin{array}{l}\text { Spread } \\
\text { (in bp) }\end{array}$} & $10 \% \mathrm{Q}$ & 4.0 & 5.0 & 4.0 & 6.0 & 7.0 & 5.0 & 25.0 & 24.0 & 21.0 \\
\hline & & mean & 11.3 & 13.1 & 20.5 & 11.6 & 13.3 & 11.1 & 56.4 & 53.5 & 50.5 \\
\hline & & median & 7.0 & 8.0 & 7.0 & 10.0 & 12.0 & 10.0 & 50.0 & 46.0 & 44.0 \\
\hline & & $90 \% \mathrm{Q}$ & 12.0 & 13.0 & 13.0 & 17.0 & 19.0 & 16.0 & 89.0 & 86.0 & 82.0 \\
\hline & \multirow{4}{*}{$\begin{array}{l}\text { Inverse } \\
\text { Depth (in } \\
\text { bp) }\end{array}$} & $10 \% \mathrm{Q}$ & 0.0 & 0.0 & 0.0 & 0.0 & 0.0 & 0.0 & 1.0 & 1.0 & 1.0 \\
\hline & & mean & 0.8 & 0.8 & 1.5 & 1.1 & 1.1 & 1.4 & 3.5 & 4.3 & 5.6 \\
\hline & & median & 0.5 & 0.5 & 0.5 & 1.0 & 0.5 & 1.0 & 2.0 & 2.0 & 3.0 \\
\hline & & $90 \% \mathrm{Q}$ & 1.0 & 1.0 & 1.5 & 2.0 & 2.0 & 2.5 & 6.5 & 8.5 & 11.0 \\
\hline & Total & $10 \% \mathrm{Q}$ & 103.0 & 100.0 & 100.0 & 97.2 & 92.5 & 95.5 & 79.0 & 78.0 & 78.0 \\
\hline & Quoted & mean & 129.2 & 125.0 & 126.1 & 120.5 & 116.6 & 120.4 & 99.9 & 100.2 & 99.1 \\
\hline & Volume & median & 132.5 & 129.0 & 130.0 & 122.5 & 118.0 & 122.8 & 102.0 & 103.0 & 102.0 \\
\hline & (in $€ \mathrm{~m})$ & $90 \% \mathrm{Q}$ & 153.0 & 147.0 & 149.5 & 143.5 & 141.5 & 143.2 & 118.5 & 118.5 & 116.5 \\
\hline
\end{tabular}

Table 1: Summary statistics of spread, inverse depth and total quoted volume. Spread is defined as the difference of the best bid and ask quotes, inverse depth as the price shift that would be induced by a trade of size $€ 15$ million and total quoted volume as the summed volume quoted at all levels of the book. 10\%Q and 90\%Q refer to the $10 \%$ and $90 \%$ quantile respectively. Statistics from sampling at one-minute intervals from 9:30 to 17:15 on all days in each sample, unavailable values are discarded. "5 year BTP 1" is the most recently issed 5y BTP in the (complete) subperiod; the full list of ISINs is given in Appendix A.

BTPs. These values slightly decrease to around $€ 120$ million in 2015 . For the very long-term titles the total quoted volume slightly evolves from ca. $€ 90$ million to around $€ 105$ million to $€ 100$ million from $2011 / 12$ to 2013 to $2014 / 15$.

Given the eventful times that our sample periods encompass we also show plots with weekly averages of spread, imbalance in inverse depth, total quoted volume and PCA1 in Figures 1 to 4 below. The leftmost two facets of each plot correspond 
to the subperiods described in Section 3.2 above. For the right facet that contains the last subperiod we have extended the descriptive Figures to December 2015 to reflect also the most recent changes in liquidity, while the subperiod used for our later analysis ends in June 2015.
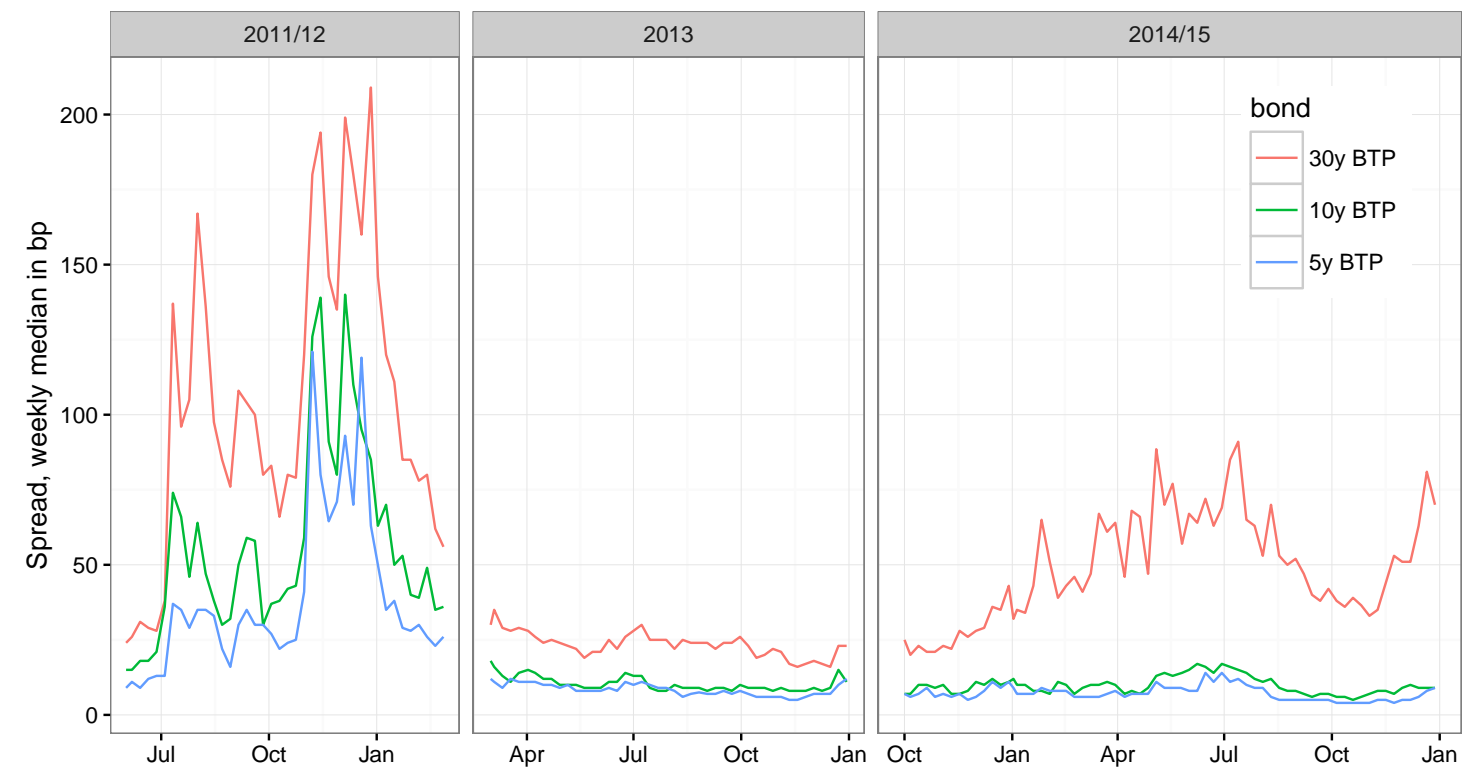

Figure 1: Weekly median of spread in basis points for the most recently issued bond for each maturity per sample. Rightmost facet extended beyond June 2015.

Figure 1 displays the median spread per week for the most recently issued bond of each maturity in each of our samples. Spread is fairly constant during the 2013 period (middle facet). While levels of spread in June 2011 were comparable to those in 2013, we see that spread peaks as the sovereign bond crisis hits Italy in July/August and November/December 2011. At the beginning of the period that we consider around Quantitative Easing, bid-ask spreads are as well comparable to those in 2013, however the spread of the 30 year BTP rises steadily from November 2014 until July 2015 and peaking again in December 2015, while the 5 and 10 year BTP remain at levels similar to 2013 for most of the period.

For inverse depth we consider the imbalance rather than the level of inverse depth in Figure 2. We calculate the imbalance of inverse depth as the inverse depth on the bid side minus inverse depth on the ask side and display the weekly mean. It is striking that inverse depth was fairly balanced in 2013 with the absolute value of the imbalance being smaller than the tick size on average (i.e. on average the limit order book is symmetric at the best). Instead for the sovereign bond crisis period we observe an asymmetric order book in several weeks for all maturities. For example the 30 year BTP stands out as heavy on the buy side by three or more basis points (on the order of magnitude of inverse depth in that period and maturity bin, c.f. Table 1) for most of December 2011. We do observe comparably large asymmetries (skewed to the bid and ask side alike) in inverse depth in 2015, especially in the 30 year BTP but also in the 5 and 10 year titles. We thus suspect that the state of market liquidity in the time of Quantitative Easing is more similar to the sovereign debt crisis than looking at the bid-ask spread and summary statistics alone suggests. 

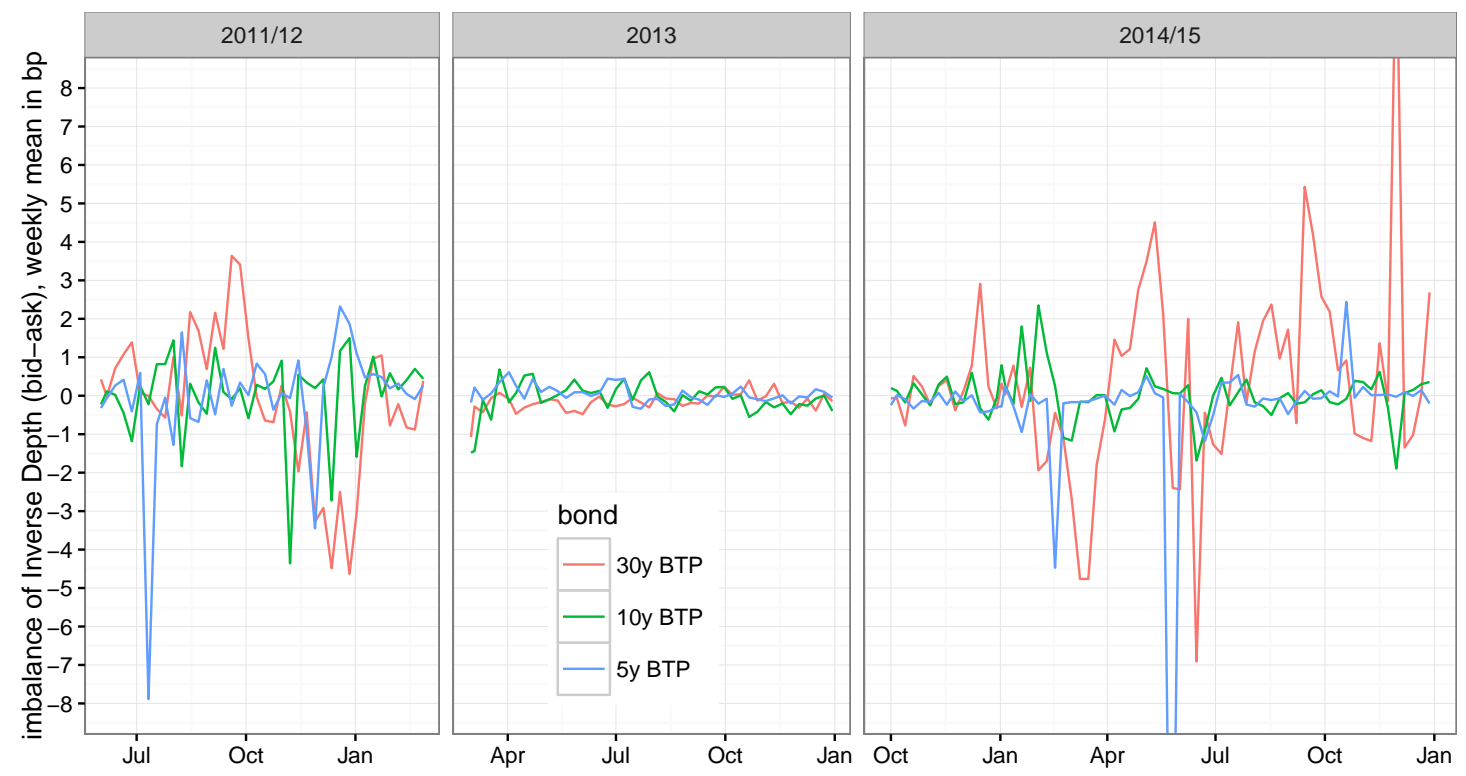

Figure 2: Weekly mean of imbalance of inverse depth in basis points for the most recently issued bond for each maturity per sample. Imbalance is calculated as the inverse depth on the bid side minus inverse depth on the ask side. Days with invalid observations were discarded. Negative values mean that virtual price impact is higher on the ask side and depth is more concentrated at or behind the best price on the bid side, i.e. there is more willingness to buy. Rightmost facet extended beyond June 2015.
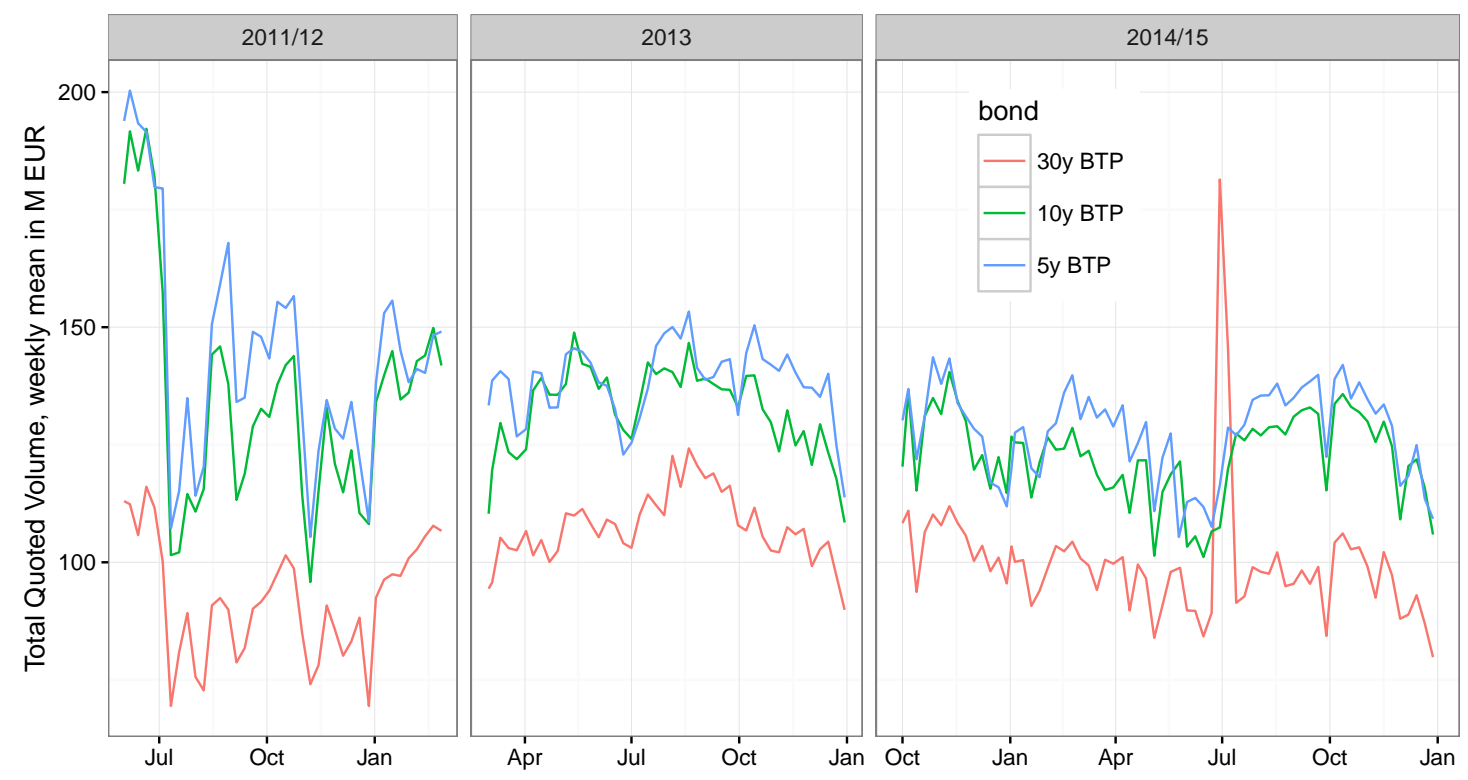

Figure 3: Weekly mean of total quoted volume in million $€$ for the most recently issued bond for each maturity per sample. Days with invalid observations were discarded. Rightmost facet extended beyond June 2015.

Figure 3 displays the mean of total quoted volume per week for the most recently 
issued bond of each maturity in each of our samples. Total volume for the 5 and 10 year BTPs was highest in June 2011, before the peak of the sovereign bond crisis, and never returned to this high levels, while for the 30 year BTP the weekly mean of total volume at the beginning and end of our crisis subperiod is roughly the same as in the 2013 period and October 2014. As above we observe significant dips in total volume in July/August and November/December 2011 during the sovereign bond crisis and a decrease in total volume from November 2014 on for all bonds. Also during 2013 we observe a dip in July and a peak in August/September. The peak in total volume in July 2015 originates from one single day with increased quoted volume on the ask side.

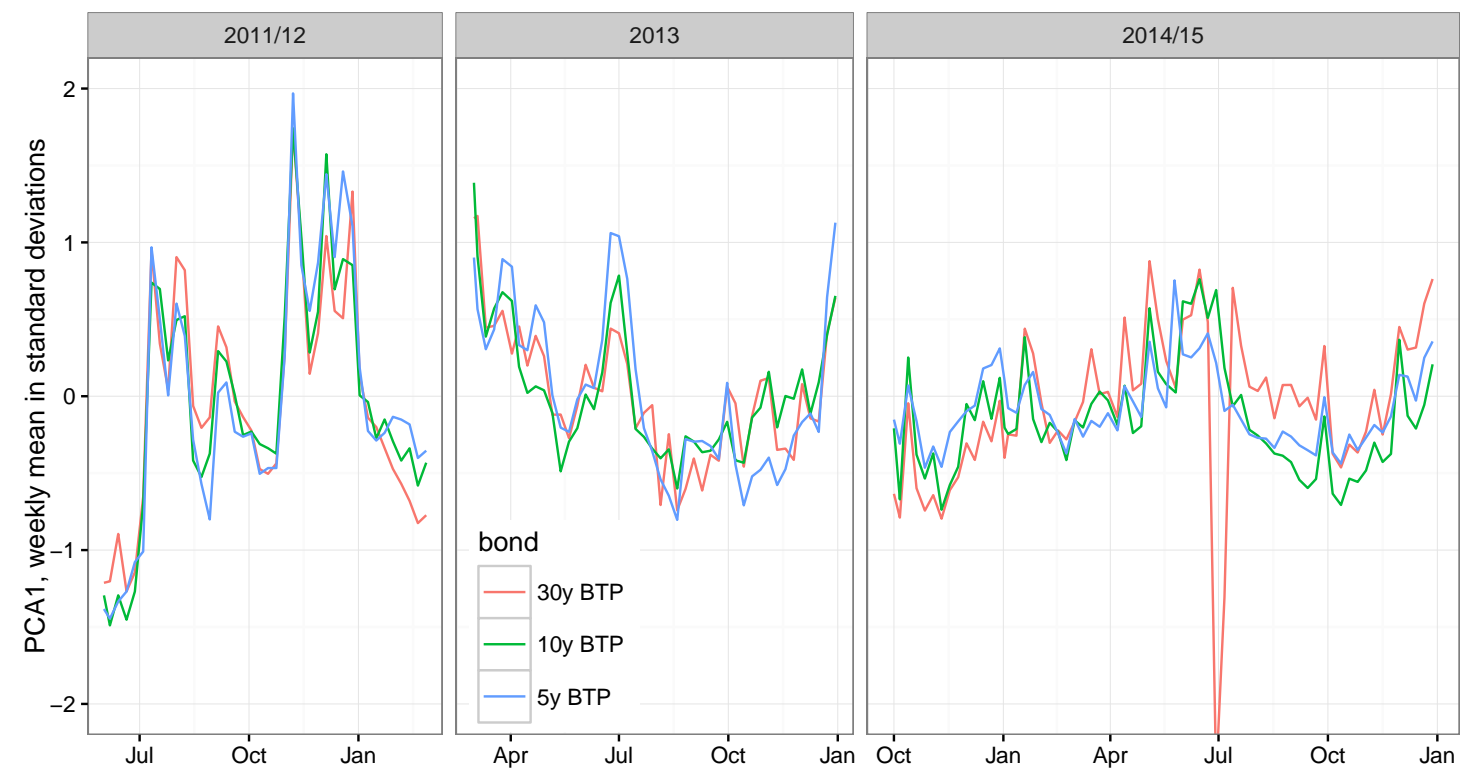

Figure 4: Weekly mean of PCA1 for the most recently issued bond of each maturity in each of our samples. Values of PCA1 are not comparable across different periods or bonds as normalization and loadings can be different. Unit is standard deviations. Rightmost facet extended beyond June 2015.

Figure 4 shows the weekly mean of PCA1 for the most recently issued bond of each maturity in each of our samples. Different from spread and total volume, these values are not comparable across samples or across bonds as the normalization coefficients are specific to each bond and sample period. We do however observe the same trends as above: sharp increases in illiquidity in July/August and November/December 2011. During 2013 we observe peaks in illiquidity in March, July and December. During the 2014/15 subperiod we observe an increase in illiquidity as well as several local peaks in illiquidity e.g. in mid-January 2015, and we find this trend for all the maturities. The dip in PCA1 in July 2015 originates from the single day with increased quoted volume on the ask side. We extend the rightmost facet beyond the sample period used for subsequent computations that ends in June 2015, using the normalization coefficients and vector loadings obtained in the sample subperiod. This extension shows an improvement of liquidity towards October 2015 and a subsequent deterioration afterwards. Throughout the extented period the liquidity of 30 year title fares worse than the 5 and 10 year BTPs. 
We proceed to quantify below the high correlation of illiquidity that is evident from the Figure.

\subsection{Commonality of Liquidity}

Commonality in liquidity is a widely documented phenomenon ${ }^{34}$ and has been found also for the data-set we are using (Coluzzi et al. (2008)). However most studies on commonality in liquidity use low-frequency measures of liquidity ${ }^{35}$ whereas our focus is on the inter-dependence of liquidity at high frequencies.

Therefore we compute the daily correlation matrix of (il-)liquidity (PCA1) from time-series sampled at one-minute intervals. That is, for each day we sample PCA1 at one-minute intervals between 9:30 and 17:15, remove the intraday pattern and compute the correlation matrix of PCA1 for that day.

\begin{tabular}{r||r|r|r} 
& 30 year BTPs & 10 year BTPs & 5 year BTPs \\
\hline \hline 30 year BTPs & 0.67 & 0.47 & 0.42 \\
\hline 10 year BTPs & 0.47 & 0.63 & 0.52 \\
\hline 5 year BTPs & 0.42 & 0.52 & 0.71 \\
\hline
\end{tabular}

Table 2: Average correlation matrix of liquidity (PCA1). Mean over daily correlation matrices from intraday time series from March 2013 through December 2013 and over bonds with same maturity. Time-series were sampled at one-minute intervals and the intraday pattern removed in the underlying liquidity metrics. Days with invalid observations were discarded.

We find a block-diagonal structure where correlation is the stronger the smaller the difference in time-to-maturity. This is consistent both across bonds and subperiods. In Table 2 we show the average intraday correlation matrix for the 2013 subperiod where we took the average both over all days in the subperiod and bonds of similar maturity. The more detailed correlation matrices split by bonds and subperiods are reported in Appendix C.

Let us summarize this section briefly: We consider liquidity via the limit order book, taking the bid-ask spread, inverse depth as a measure of the shape of the book near the best and total quoted volume as a our liquidity metrics and constructing a condensed PCA measure from these. Liquidity is decreasing in maturity, i.e. 30 year BTPs are the most illiquid. Liquidity is correlated across bonds and this correlation is the stronger, the smaller the difference in maturity between bonds. We observe several peaks in illiquidity in 2011/12 during the European sovereign bond crisis, with especially spread increasing dramatically. Over our 2013 period liquidity remains mostly stable. In 2014/15 we observe a steady increase in illiquidity. This is especially visible in the spread of the 30 year title but we also observe a decrease in quoted volume across all maturities.

\footnotetext{
${ }^{34}$ See the review in Section 2 and references therein.

${ }^{35}$ Fleming (2003) and Coluzzi et al. (2008) use weekly observations.
} 


\section{Reaction to Liquidity Shocks}

In this section we analyze the reaction of liquidity in response to liquidity shocks. A standard technique is to use orthogonalized impulse responses, an approach pioneered by Sims (1980). In this approach the Cholesky decomposition to orthogonalize the underlying shocks requires a prior specification of the ordering of the variables as discussed e.g. in Lütkepohl (1991). Since we cannot make an assumption on the ordering of the liquidity of different bonds, we prefer to use the generalized variance decomposition proposed by Koop et al. (1996) and Pesaran and Shin (1998) that is invariant to the ordering of variables in the VAR. ${ }^{36}$ The main difference is that instead of considering the variance caused by a shock that is orthogonal to shocks in prior components, generalized variance decomposition uses a shock vector that is standardized in one component and contains proportionate innovations in the other components that correspond to the observed co-variation structure of innovations.

The $H$-step generalized variance decomposition $d_{i j}(H)$ is defined as the proportion of the $H$-step ahead forecast error variance of $i$ which is accounted for by the innovations in $j$ in the VAR model defined in equation (2):

$$
d_{i j}(H)=\frac{\sum_{h=0}^{H-1}\left(\mathbb{E}\left[x_{i, t+h} \mid \epsilon_{j, t}=\sqrt{\sigma_{j j}}, \boldsymbol{\Sigma}\right]-\mathbb{E}\left[x_{i, t+h} \mid \boldsymbol{\Sigma}\right]\right)^{2}}{\mathbb{E}\left[\left(x_{i, t+H}-x_{i, t}\right)^{2}\right]} .
$$

To forecast $\boldsymbol{x}_{t}$ we assume the following VAR model of liquidity

$$
\boldsymbol{x}_{t}=\sum_{l=1}^{L} \boldsymbol{\Phi}_{l} \boldsymbol{x}_{t-l}+\boldsymbol{\epsilon}_{t}
$$

where $\boldsymbol{x}_{t}$ is a $N \times 1$ vector of PCA1 of the $N$ bonds at time $t, L$ is the number of lags, $\boldsymbol{\Phi}_{l}$ is the $N \times N$ coefficient matrix of the VAR at lag $l \in\{1, \ldots, L\}$ and $\boldsymbol{\epsilon}_{t}$ is the $N \times 1$ vector of idiosyncratic shocks at time $t$.

To calculate $d_{i j}(H)$ we make the following standard assumptions ${ }^{37}$ on the VAR model in equation (2)

1. $\mathbb{E}\left[\boldsymbol{\epsilon}_{t}\right]=\mathbf{0}, \mathbb{E}\left[\boldsymbol{\epsilon}_{t} \boldsymbol{\epsilon}_{t}^{\prime}\right]=\boldsymbol{\Sigma}$ where $\boldsymbol{\Sigma}$, is the $N \times N$ positive definite covariance matrix of the idiosyncratic component of the VAR, and $\mathbb{E}\left[\boldsymbol{\epsilon}_{t} \boldsymbol{\epsilon}_{t^{\prime}}^{\prime}\right]=\mathbf{0} \forall t \neq t^{\prime}$.

2. All roots of $\left|\mathbb{1}-\sum_{l=1}^{L} \boldsymbol{\Phi}_{l} z^{l}\right|=0$ lie outside the unit circle, i.e. $\boldsymbol{x}_{t}$ is covariancestationary

We can therefore re-write equation (2) as an infinite MA model:

$$
\boldsymbol{x}_{t}=\sum_{l=0}^{\infty} \boldsymbol{A}_{l} \boldsymbol{\epsilon}_{t-l}
$$

\footnotetext{
${ }^{36}$ Generalized Variance Decomposition has been applied e.g. to construct connectedness measures from daily volatility time-series of US financial institutions (Diebold and Yllmaz (2014)), to document susceptibility of returns of currency futures to shocks (Elyasiani et al. (2007)), to find spillover of volatility between ETFs and their component stocks (Krause et al. (2013)) and in the field of energy economics, see for example Papapetrou (2001).

${ }^{37}$ See e.g. Lütkepohl (1991) Chapter 2 and Pesaran and Shin (1998)
} 
with the $N \times N$ coefficient matrices $\boldsymbol{A}$ given through the recursive relations $\boldsymbol{A}_{i}=$ $\sum_{l=1}^{\min (L, i)} \boldsymbol{\Phi}_{l} \boldsymbol{A}_{i-l}$ and $\boldsymbol{A}_{0}=\mathbb{1}$. The $H$-step generalized variance decomposition defined in equation (1) is then given as

$$
d_{i j}(H)=\frac{\sigma_{j j}^{-1} \sum_{h=0}^{H-1}\left(\boldsymbol{e}_{i}^{\prime} \boldsymbol{A}_{h} \boldsymbol{\Sigma} \boldsymbol{e}_{j}\right)^{2}}{\sum_{h=0}^{H-1}\left(\boldsymbol{e}_{i}^{\prime} \boldsymbol{A}_{h} \boldsymbol{\Sigma} \boldsymbol{A}_{h}^{\prime} \boldsymbol{e}_{i}\right)}
$$

with $\boldsymbol{\Sigma}=\mathbb{E}\left[\boldsymbol{\epsilon}_{t} \boldsymbol{\epsilon}_{t}^{\prime}\right]$ the covariance matrix of the idiosyncratic component of the VAR and $\sigma_{i j}=\Sigma_{i j}$.

In practice we choose $L$ with the AIC under a maximum lag constraint of $L \leq 10$ (i.e. 10 minutes) and consider a forecast horizon of 10 minutes $(H=10)$. We do not remove the intraday-pattern of liquidity as the result is unaffected.

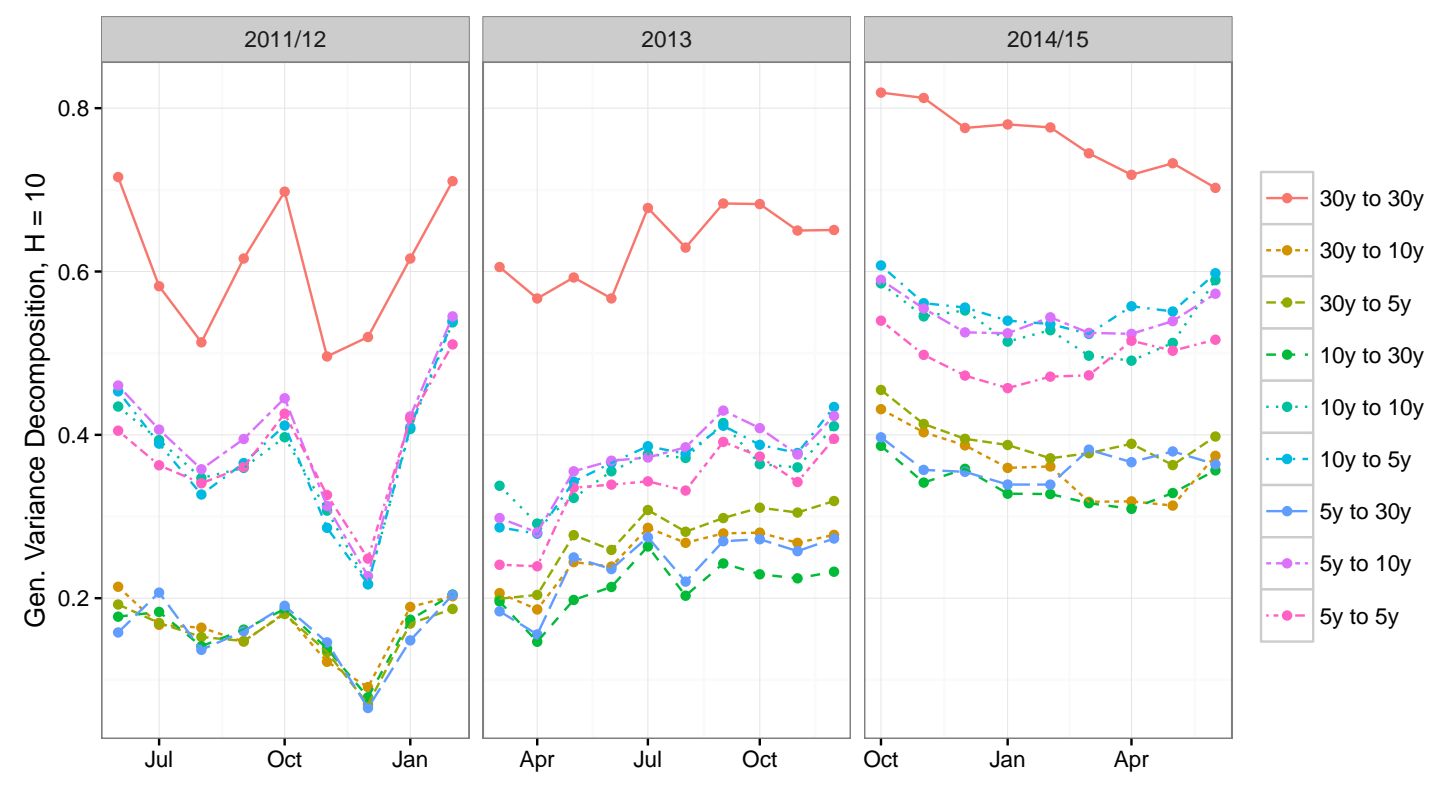

Figure 5: Average Generalized Variance Decomposition for a forecast horizon of 10 minutes $(H=10)$, cross-asset components. Mean of daily estimations per month and maturity grouping. Time-series sampled at one-minute intervals without removal of the intraday pattern. Days with invalid observations were discarded. The label "5y to 30y" refers to the variation in 30 year BTPs caused by shocks to 5 year BTPs, the label "30y to 30y" refers to the variation in 30 year BTPs caused by shocks to different 30 year BTPs.

Figure 5 shows the average generalized variance decomposition for a forecast horizon of 10 minutes $(H=10)$. There are three well-separated bands: Shocks on one 30 year BTP explain ca. $70 \%$ of variation in other 30 year BTPs. The second band is shocks between different 5 and 10 year BTPs. Surprisingly we do not see a separation between 5 and 10 year BTPs here, i.e. their regular liquidity dynamics are strongly coupled. The weakest connection is between 30 year and 5 or 10 year BTPs, with neither a distinction for direction (from/to 30 year BTPs) nor between the 5 and 10 year BTPs as in the second band. ${ }^{38}$

\footnotetext{
${ }^{38}$ The diagonal elements, i.e. the liquidity variation in one asset as a reaction to shocks in the same asset, are typically explained to $80-90 \%$. We report the corresponding figure in Appendix D.1.
} 
In the first subperiod we observe two dips in August and November/December of 2011, while for the 2013 subperiod there is a general increase in $d_{i j}(H)$. During the $2014 / 2015$ period $d_{i j}(H)$ is higher than in the two previous periods.

A downside of the generalized variance decomposition is that the contributions from different shocks are no longer normalized as for the case of orthogonal shocks. Diebold and Yllmaz (2014) use a row-normalized version of $d_{i j}(H)$ to overcome this and we show our corresponding results in Appendix D.2.

Let us stress that our finding that a high share of variation is explained by the effect of shocks in other bonds is due to the correlated nature of the shocks. Specifically they are chosen to represent the empirical structure of shocks: $\mathbb{E}\left[\boldsymbol{\epsilon}_{t} \mid \epsilon_{j t}=\right.$ $\left.\sqrt{\sigma_{j j}}\right]=\boldsymbol{\Sigma} \boldsymbol{e}_{j} / \sqrt{\sigma_{j j}}$ and the high values of $d_{i j}(H)$ arise from the large cross-correlation that is present in $\Sigma .^{39}$

When instead we construct shocks to purely one component by using only the diagonal of $\boldsymbol{\Sigma}$ in the equation (4) above ${ }^{40}$ the corresponding values of $d_{i j}(10)$ where $i \neq j$ descend to approximately $10 \%$ and the band structure vanishes. The corresponding plot is shown in Appendix D.3. We thus deduce that the idiosyncratic term is the main driver of commonality in liquidity and the band structure that we observe in this section. This also implies that the majority of the dynamics of (il-)liquidity happens at time-scales much shorter than our sampling frequency (1 minute). Therefore in the following section we investigate the dynamics in the tail of the liquidity distribution in a (quasi-)continuous framework.

\section{Liquidity Shocks in the Tail and Spillover Ef- fects}

So far we have considered the reaction to illiquidity shocks in the mean and found no evidence of a significant lead-lag relationship ${ }^{41}$ but rather that commonality arises from the contemporaneous correlation in the idiosyncratic shock term.

We now turn our attention to the tail of the distribution of liquidity. This is of importance since liquidity is crucial especially when it is scarce. Investors, issuers and regulators alike are worried about so-called "dry-ups" of liquidity when virtually all quotes disappear from one or both sides of the limit order book and trading, even at extreme prices, becomes impossible.

When looking in detail to such dry-ups of liquidity we observe that one liquidity metric by itself is not enough to capture the developments in all of the limit order book. $^{42}$ Therefore we use only PCA1 in this section as it unifies all the different aspects of liquidity and is less susceptible to spurious effects in the underlying liquidity metrics. The impression is further that often in the run-up to a dry-up

\footnotetext{
${ }^{39}$ The results from this section are thus in line especially with the cross-correlation that we observe in Section 4.3. Note however that $\boldsymbol{\Sigma}$ is the correlation matrix of the idiosyncratic term $\boldsymbol{\epsilon}_{t}$ in equation (2) whereas in Section 4.3 and Appendix $\mathrm{C}$ we show the correlation matrix of liquidity, i.e. the $\boldsymbol{x}_{t}$ in equation (2).

${ }^{40}$ Thus also replacing $\boldsymbol{\Sigma}$ in the numerator of equation (4).

${ }^{41}$ E.g. the "5y to $30 y$ " component in Figure 5 is of similar size as the "30y to $5 y$ " component.

${ }^{42}$ E.g. Spread often initially becomes smaller before a dry-up while many participants already suspend their quotes, thus decreasing the total quoted volume. Therefore spread alone would give a false impression of liquidity that is not deep. See Appendix E.1 for an example.
} 
the order book thins out while quotes at the best initially remain stable. When those quotes at the best are retreating, also other participants are unwilling to be at the best (and thus most vulnerable to adverse selection if a market order were to arrive) and remaining participants stepwise widen their quotes when they find that other participants are acting similarly. ${ }^{43}$

We take this into account in Section 6.1 below when devising our illiquidity event detection strategy. Instead of looking for extreme "jumps" we detect smaller "rushes" to illiquidity. Our idea is then, that a (quick) succession of such illiquidity events, an "illiquidity cascade" is dangerous and lays the ground for the extreme event. This is especially so, when the dynamics towards illiquidity is fueled by itself, i.e. traders or algorithms observing that their peers are disappearing from the book or widening their spread are inclined to do the same. To capture this aspect of self-excitation we model the process of illiquidity events as a Hawkes process in Section 6.2. In Section 6.3 we proceed to interpret these results as two new metrics of liquidity: resilience and spillover of illiquidity in the tail. The advantages of this approach are that we can focus specifically on the tail of the liquidity distribution and gain a directed measure of spillover, allowing us to identify assets which lead or lag in illiquidity contagion.

\subsection{Detection of Illiquidity Events}

We detect an illiquidity event, i.e. a shock to liquidity or a "rush" to illiquidity, in continuous time when there is a large and abrupt decrease in liquidity. Precisely, an illiquidity event is detected anytime the velocity of increase in illiquidity over a period of $l$ updates of the limit order $\operatorname{book}^{44}$ is above a given threshold $\theta .{ }^{45}$ The counting process $N^{i}(t)$ of illiquidity events of bond $i$ at time $t$ is then defined as

$$
N^{i}(t)=\sum_{m=0}^{M^{i}(t)} \mathbb{1}_{\frac{P C A 1^{i}\left(t_{m}\right)-P C A 1^{i}\left(t_{m-l}\right)}{t_{m}-t_{m-l}}>\theta}
$$

where $M^{i}(t)$ is the number of updates of $P C A 1^{i}$ up to time $t$ and $t_{m}$ the physical time corresponding to update $m$. In order to model illiquidity events and not limit order book activity we do not detect illiquidity events when an illiquidity event has already been detected within $l$ limit order book updates of the possible limit order book event, or in other words, there need to be at least $l$ limit order book updates between two illiquidity events. Our approach takes into account both physical and (limit order book-)event time. The detection algorithm is triggered in limit order book-time, taking into account the different trading activity in different bonds (e.g. very long term bonds are less actively traded). The velocity of increase in illiquidity instead is normalized by physical time elapsed.

\footnotetext{
${ }^{43}$ Our observations suggest that there is a structure of confident participants that are willing to be at the best and following participants that make their quotes relative to other market participants. This has been confirmed in conversations with market participants.

${ }^{44}$ We recall that the limit order book is updated instantaneously every time that a participant enters, changes or suspends/removes a quote.

${ }^{45}$ We thus do not consider extreme movements towards liquidity as they are more rare and no threat to the functioning of the market.
} 
For the application to the data below and in Section 6.3 the lag $l$ is chosen as the average number of PCA1 updates over 30 seconds and the threshold $\theta$ as the $95 \%$ percentile of all velocities $\frac{P C A 1^{i}\left(t_{m}\right)-P C A 1^{i}\left(t_{m-l}\right)}{t_{m}-t_{m-l}}$. In Appendix E.2 we show a snapshot from the limit order book with detected events as an illustration of the event detection results.

We detect a mean of ca. 119 illiquidity events per bond and day and a median of 78. This is roughly consistent across periods and bonds. We report detailed statistics of illiquidity events and provide a discussion in Appendix F.

\subsection{Hawkes Processes}

Hawkes processes ${ }^{46}$ are point processes $N^{i}(t)$ where the intensity $\lambda^{i}(t)$ depends on the past history of the process. For the process of illiquidity events of asset $i$ the intensity reads

$$
\lambda^{i}(t)=\mu^{i}+\int_{-\infty}^{t} \Phi^{i i}(t-s) \mathrm{d} N^{i}(s)+\sum_{j \neq i} \int_{-\infty}^{t} \Phi^{i j}(t-s) \mathrm{d} N^{j}(s)
$$

where $\mu^{i}$ accounts for a constant baseline intensity and $\boldsymbol{\Phi}(t)$ is a kernel matrix with positive elements and spectral norm $<1$. The diagonal elements $\Phi^{i i}$ determine the self-exciting behavior of the process while the off-diagonals $\Phi^{i j}, j \neq i$ describe cross-excitation from $j$ to $i$.

The motivation for this parametrization is that we can compute the fraction of events that is explained by each of these terms as detailed below and attribute them an economic interpretation.

Firstly, the higher the fraction of events in asset $i$ explained by cross-excitation from asset $j$ the more likely it is that illiquidity shocks propagate from $j$ to $i$, i.e. asset $i$ is more susceptible to shocks in asset $j$. If instead this fraction is 0 then asset $i$ is perfectly resilient to shocks in asset $j$ and unaffected by any events in $j$. We therefore consider the fraction of events explained by cross-excitation a measure of irresilience or fragility (and therefore illiquidity) of asset $i$ along the cross-asset dimension. We can in principle construct a bi-directional network where the strength of the directional connections from $j$ to $i$ is a function of the fraction of events in asset $i$ explained by cross-excitation from asset $j$. If the fraction of events explained by cross-excitation is significantly higher from $j$ to $i$ than from $i$ to $j$ then asset $j$ is leading asset $i$ in illiquidity and illiquidity shocks tend to spillover from asset $j$ to $i$. From a policy perspective it would then make sense to monitor and target especially the asset that causes the spillover (i.e. $j$ in this example) to avoid contagion to other assets that are susceptible to its shocks.

Second, a higher fraction of self-excited events in asset $i$ means that past shocks are more likely to incite more shocks instead of abating. If this fraction is 0 then shocks in that asset never lead to further shocks in the same asset (and thus arrive either randomly or from other assets); if instead it is close to 1 then almost any shock has been stirred up by previous shocks and is also likely to provoke further illiquidity events, potentially leading to a market liquidity dry-up in a vicious circle. Thus the fraction of events explained by self-excitation is a measure of irresilience or fragility

\footnotetext{
${ }^{46}$ Hawkes (1971a) and Hawkes (1971b)
} 
and illiquidity along the time dimension.

Lastly, the fraction of events explained by the baseline intensity captures events that can neither be attributed to self- nor cross-excitation. If this fraction is 1 then all illiquidity events arrive randomly with constant intensity (thus mathematically $\lambda^{i}(t)=\lambda^{i}$ describing a Poisson process) and shocks do not propagate, neither from other assets nor in time. Therefore we interpret the fraction of baseline events as a measure of resilience and liquidity.

Let us point out here that one should consider the differences rather than the levels of these fractions informative. As detailed in equation (12) below the fractions are constrained to add up to $1 .{ }^{47}$ So the information carried by statements such as "the fraction of self-excited events this month was 0.5 " is that there is no complete resilience in the time dimension. The news "the fraction of self-excited events has doubled to 0.5 since last month" in combination with an assessment of the market behavior of the last month could be a flag for caution depending on the circumstances not specified in this example.

To parametrize the decay kernel $\boldsymbol{\Phi}(t)$ of event excitation in equation (6) above we choose an exponential kernel

$$
\Phi^{i j}(t-s)=\sum_{k=1}^{P_{i j}} \alpha_{k}^{i j} \exp \left(-\beta_{k}^{i j}(t-s)\right)
$$

with a double exponential kernel $\left(P_{i i}=2\right)$ for the self-exciting component and a single exponential $\left(P_{i j}=1, i \neq j\right)$ for the cross-excitation terms. ${ }^{48}$

Let us from now on without loss of generality look to pairs of assets, i.e. $i, j \in$ $\{1,2\}$. Equation (6) then becomes

$$
\begin{aligned}
& \lambda_{1}(t)=\mu_{1}+\int \Phi_{11}(t-s) \mathrm{d} N_{1}(s)+\int \Phi_{12}(t-s) \mathrm{d} N_{2}(s) \\
& \lambda_{2}(t)=\mu_{2}+\int \Phi_{22}(t-s) \mathrm{d} N_{2}(s)+\int \Phi_{21}(t-s) \mathrm{d} N_{1}(s)
\end{aligned}
$$

and by assuming stationarity and taking the mean we get

$$
\begin{aligned}
& \Lambda_{1}=\mu_{1}+\gamma_{11} \Lambda_{1}+\gamma_{12} \Lambda_{2} \\
& \Lambda_{2}=\mu_{2}+\gamma_{22} \Lambda_{2}+\gamma_{21} \Lambda_{1}
\end{aligned}
$$

where $\gamma_{i j}=\int_{0}^{\infty} \Phi^{i j}(t) \mathrm{d} t$ is the time-integral of the $i j$ component of the kernel, i.e. for our exponential kernel $\gamma_{i j}=\sum_{P} \alpha_{i j}^{P} / \beta_{i j}^{P}$, and $\Lambda_{i}$ is the average intensity of process $i$. Dividing equation (10) by $\Lambda_{1}$ gives the respective fractions of events in process 1 that are explained by the baseline intensity, self- and cross-excitation respectively:

$$
1=\frac{\mu_{1}}{\Lambda_{1}}+\gamma_{11}+\gamma_{12} \frac{\Lambda_{2}}{\Lambda_{1}}
$$

\footnotetext{
${ }^{47}$ Furthermore note, as detailed above, that these measures are sample-specific for two normalizations we make. First the scaling to construct the PCA-measure is sample- and asset-specific and second, so is the threshold that is chosen in the event definition.

${ }^{48} \mathrm{We}$ can further interpret the $\alpha$-terms in equation (7) as capturing fragility (the amplitude of reaction to an illiquidity shock) whereas the $\beta$-terms are related to resilience: the larger $\beta$ the quicker the arrival intensity of shocks decays. Our approach combines both of these facets when we calculate the norm of the kernel below.
} 
and analogously for process 2 .

Empirically we proceed as follows. First we estimate the Hawkes parameters separately for each estimation period and each pair of bonds via a maximum-likelihood estimation. In a second step we discard estimations where the estimated Hawkes process is non-stationary, i.e. has a spectral radius $\geq 1$. Third we compute the stationary intensities $\Lambda_{1}$ and $\Lambda_{2}$ from equations (10) and (11) and in the last step we compute the fractions as in equation (12). We interpret and present the results of this approach in the next section.

Let us point out another possible application of our approach. Given the model parameters from the estimation (step 1 above) we could carry out an impulseresponse analysis, i.e. calculate the probability or increase in probability of illiquidity events happening in one asset during a response time due to an impulse (or shock) given as illiquidity events in the same or paired assets.

\subsection{Empirical Results}

We perform the estimation procedure lined out above for our subset of the three most recently issued 5, 10 and 30 year fixed-rate Italian government bonds (BTPs), choosing days as the estimation period. ${ }^{49}$ In addition in the second step above we also discard estimations when there are less detected illiquidity events than estimation parameters (14) in one of the bonds to avoid over-fitting. For every estimation (i.e. day and pair) we calculate the fraction of illiquidity events of bond $i$ attributed to cross-excitation, self-excitation from the paired bond $j$ and baseline intensity.

In Figures 6 through 8 below we display the mean per month and maturity or pairing of maturities of each of the fraction of events explained by cross-excitation, self-excitation and the baseline intensity respectively.

Figure 6 shows the average fraction of illiquidity events explained by crossexcitation, distinguishing by the maturity bin to which the spillover is directed, i.e. Figure 6 a shows spillover to 5 year BTPs, Figure $6 \mathrm{~b}$ spillover to 10 year BTPs and Figure 6c spillover to 30 year BTPs from all the three maturity bins. Spillover within one maturity bin, e.g. 30 year to 30 year, means spillover from different bonds of the same maturity bins but is different from self-excitation.

A higher fraction of cross-excited events means illiquidity shocks are more likely to propagate across different maturities so the bonds are more fragile/less resilient to shocks in other bonds. The fraction of events explained by cross-excitation is thus a measure of illiquidity and illiquidity spillover or connectedness in the tail of the liquidity distribution of different bonds.

We are cautious to compare the three subperiods directly, but it does stand out that in 2014/15 a far higher fraction of events is explained by cross-excitation than in 2011/12, a rise that already manifests itself in $2013 .^{50}$ Let us further point out, that while in 2011/12 a block-diagonal structure, where cross-excitation is strongest for bonds of the same maturity, is clearly present, this no longer holds

\footnotetext{
${ }^{49}$ I.e. the core hours of one trading day from 9:30 to 17:15. We thus avoid the problem of overnight returns. In principle also shorter estimation periods are possible, as long as there are enough illiquidity events to estimate the model parameters reliably.

${ }^{50} \mathrm{We}$ also observe a rise in the average number of quote updates per day across samples. We conjecture that participants might have gone to monitoring liquidity across bonds more closely.
} 

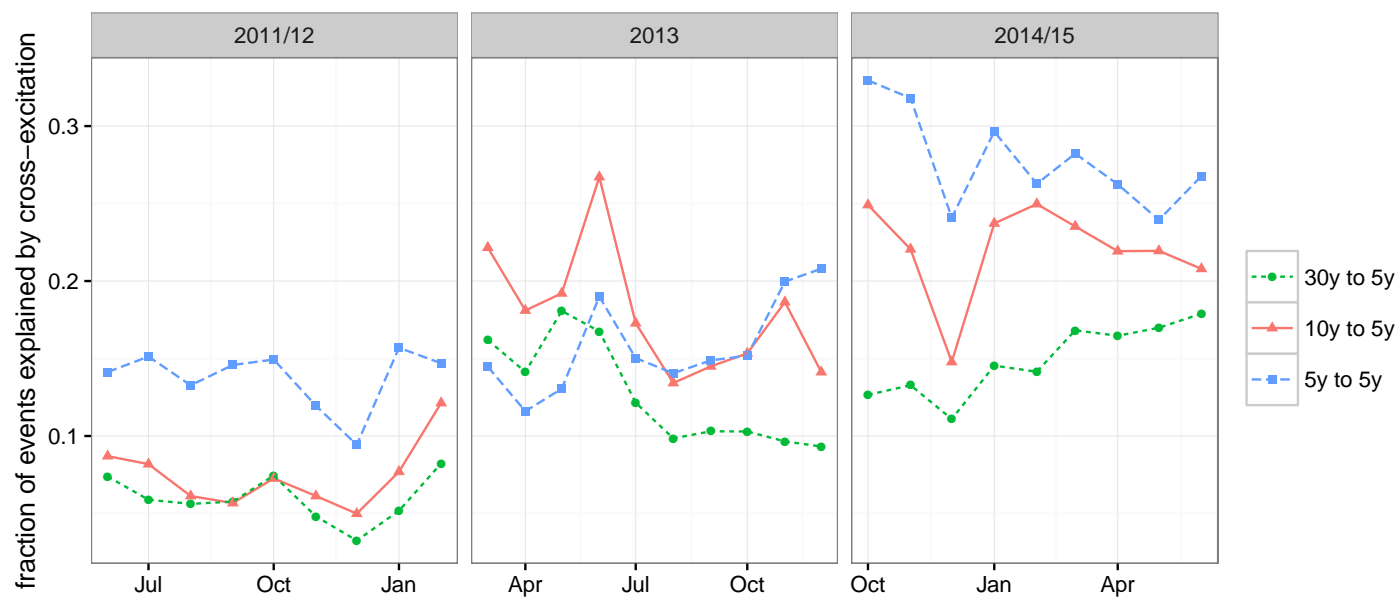

(a) to 5 year BTPs
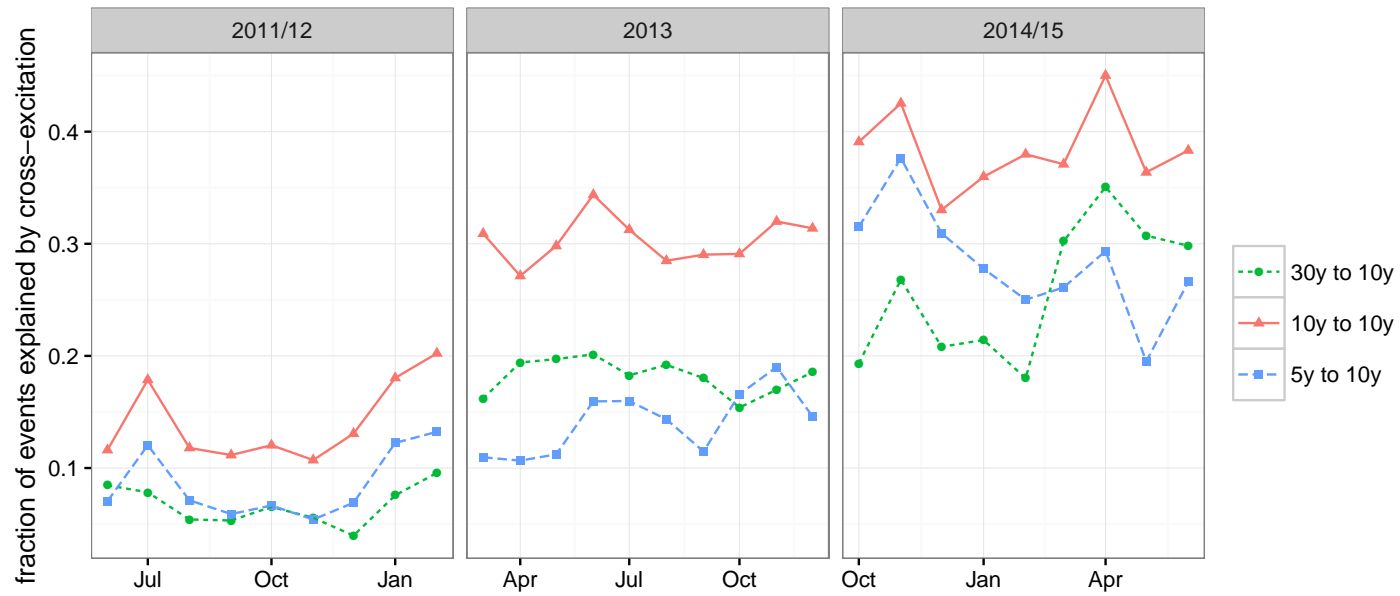

(b) to 10 year BTPs
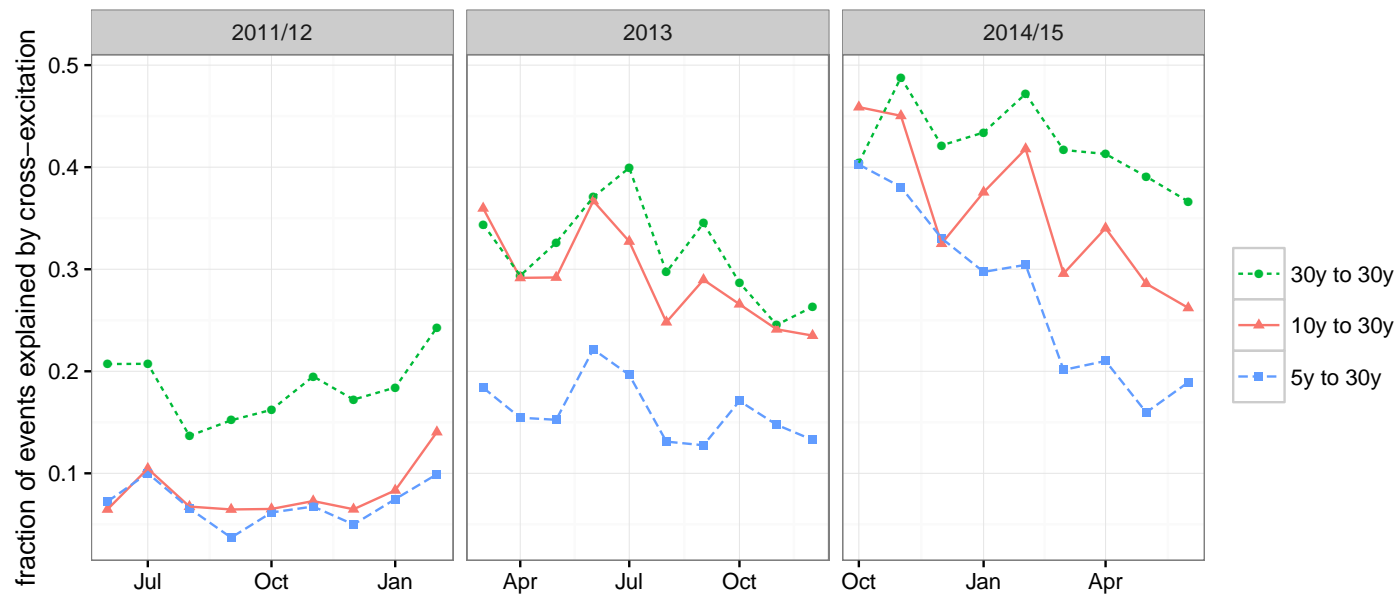

(c) to 30 year BTPs

Figure 6: Average fraction of illiquidity events explained by cross-excitation. A higher fraction of cross-excited events means illiquidity shocks are more likely to propagate across different maturities. Mean of daily estimations per month and maturity pairing, days with non-stationary estimations were discarded. "5y to 30y" refers to the fraction of illiquidity events in 30 year BTPs explained by events in 5 year BTPs. 
in 2013. Instead in 2013 cross-excitation from 10 year BTPs to 5 year BTPs is stronger or as strong than between different 5 year BTPs, while cross-excitation from 10 year to 30 year BTPs is on par with that from 30 year to (different) 30 year BTPs. This does not hold the other way round, i.e. the influence of the 30 year and the 5 year on the 10 year BTP is typically weaker. Therefore we conclude that in 2013 the 10 year BTPs had a benchmark status in the tail of the liquidity distribution, with illiquidity shocks spreading via the 10 year titles.

In the last subperiod around Quantitative Easing we still find that the 5 year titles are strongly influenced by the 10 year BTPs and much more strongly so than by 30 year titles, however the influence from titles of the same maturity is strongest here, unlike as in much of 2013. The 10 year BTPs were strongly related to 5 year titles in late 2014, this however diminishes in 2015 and instead from March 2015 (the month when Quantitative Easing was implemented) illiquidity shocks from the 30 year BTP explain a much higher fraction of such shocks in the 10 year titles. The very long-term 30 year titles appear very related in the tails to both the 5 and the 10 year BTPs in the beginning of the subperiod, but gradually show less cross-excited events, a decrease that is strongest for events cross-excited from different maturities, with a notable decline from February to March 2015. This gives a picture that the 30 year bonds are both becoming more illiquid and spill over more from the 30 year bonds to other maturities.
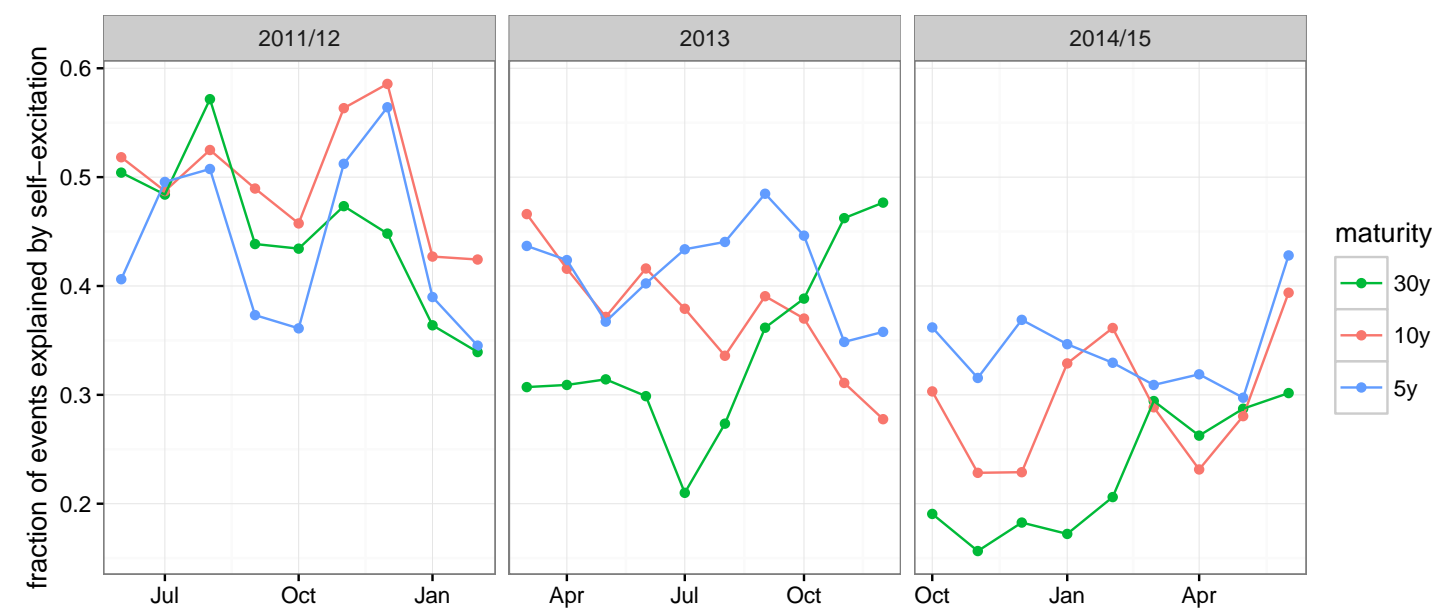

Figure 7: Average fraction of illiquidity events explained by self-excitation. A higher fraction of self-excited events means illiquidity shocks are more likely to amplify and propagate in time and market liquidity is more fragile or less resilient along the time dimension.

Figures 7 and 8 show the average fraction of illiquidity events explained by selfexcitation and baseline events respectively. Since by equation (12) the fractions must sum up to 1 , we decide to analyze these together. A higher fraction of selfexcited events means illiquidity shocks are more likely to amplify and propagate in time and fragility to illiquidity shocks is higher along the time dimension. The fraction of self-excited events is thus a measure of illiquidity. The fraction of baseline events instead measures resilience to liquidity shocks: it is high if many events arrive just randomly and are not caused by either self- or cross-excitation, thus it 


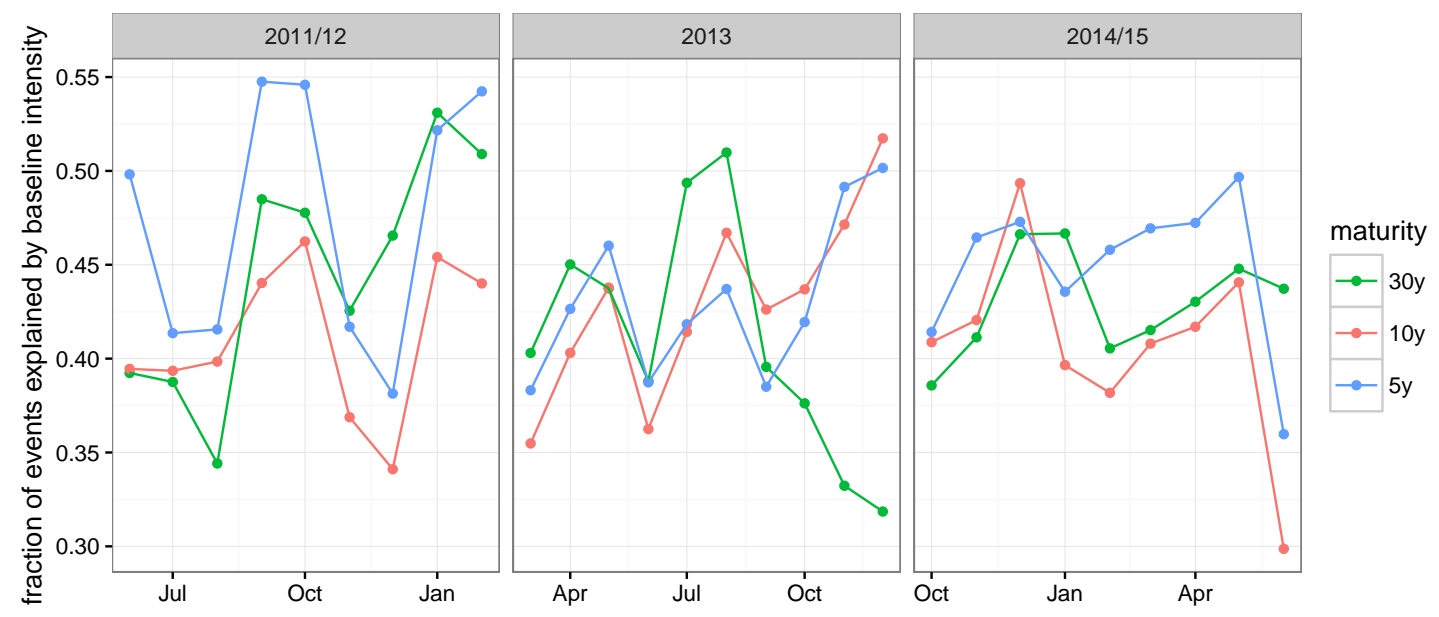

Figure 8: Average fraction of illiquidity events explained by the baseline intensity. The fraction of baseline events measures resilience to liquidity shocks.

is a metric of liquidity.

Looking at the 2011/12 subperiod both measures indicate decreased resilience to illiquidity shocks in July/August and November/December 2011. That is in agreement with our expectations given that these periods were at the core of the sovereign bond crisis and liquidity was fragile, with illiquidity metrics rising to unsustainably large levels in precisely these periods.

In 2013 resilience peaks in July/August, especially for the 30 year BTPs. It follows a decrease in resilience for the 30 year titles while the 5 and 10 year bonds become more resilient towards December 2013.

For the Quantitative Easing period we see a peak in resilience in the tails in December 2014. After a drop in January/February 2015 resilience then increases until May across maturities and drops steeply in June 2015 for the 5 and 10 year titles.

Let us repeat that one should be cautious as to what measures can be compared across periods (or bonds) as we do make a set of normalization choices: first when computing the PCA and the threshold for illiquidity events and second when we normalize fractions to sum up to 1 . When in doubt we suggest to consider the differences over time in the context of their respective sample periods rather than the levels. Having made this disclaimer we do however carefully suggest that the fractions of events attributed to the different excitation channels are comparable across assets and periods, precisely because they are normalized to sum to 1 .

\section{Conclusion}

Illiquidity risks and especially dry-ups of liquidity are a major threat to the functioning of financial markets and thus a concern both to investors and regulators. We propose a new identification and modeling approach to detect when the reactions of market participants to illiquidity shocks are susceptible to becoming a self-enforcing circle that leads to dry-ups of liquidity and a collapsing of the market and when there is spillover of illiquidity across assets. This approach gives a 
directional measure of illiquidity spillovers and resilience or fragility to illiquidity shocks specifically in extreme events that we compare with the regular reaction to liquidity impulses.

Our analysis is set in the sovereign bond market of the Eurozone from 2011 through 2015, encompassing core parts of the European sovereign debt crisis, the start of Quantitative Easing by the ECB and most recently the regime of extremely low bond yields.

We suggest that liquidity is too intricate to be measured by one metric (e.g. bid-ask spread) alone and use a condensed measure of limit order book liquidity.

As expected we find that market liquidity is more fragile (in extreme events) and less predictable (in the regular response to liquidity shocks) when an asset is very illiquid.

While the variance decomposition for the regular dynamics reveals that liquidity is consistently grouped into medium- and long-term bonds on one side and very long-term bonds on the other side, in the study of tail events we find that the market has become more integrated or interconnected in illiquidity since 2011. The structure of illiquidity spillover has changed from a pure block-structure grouped by maturity to a more complex dynamics. We observe that for much of 2013 the 10 year BTPs had as strong an effect on the 5 and 30 year BTPs as other bonds of similar time-to-maturity, that is the 10 year titles assumed a benchmark role as driver of illiquidity spillover. In 2015 the 10 year titles are less influential, however we observe that, at the same time when the implementation of Quantitative Easing starts, the 30 year bonds are both becoming more illiquid and spill over more to other maturities.

At the same time in the levels we find that, while the 5 and 10 year titles are liquid and stable in 2015, the 30 year titles have turned illiquid, with bid-ask spreads as high as during the sovereign bond crisis. This is worrisome from a policy perspective as now liquidity shocks are spreading from the weakest element of the chain. We conjecture that, among the other possible reasons stated in the introduction, the illiquidity of the very long-term bonds might be related to the unusually low yields that prevent profitable market making, while the illiquidity spillover channel opens as the yield curve flattens and 10 year yields become comparable to 30 year yields. Thus, when managing the yield curve, policymakers should strive to make these bonds that drive illiquidity more attractive to avoid contagion of illiquidity across maturities. 


\section{References}

Aït-Sahalia, Y. (2004). Disentangling diffusion from jumps. Journal of Financial Economics $74(3), 487-528$.

Aït-Sahalia, Y., J. Cacho-Diaz, and R. J. Laeven (2015). Modeling financial contagion using mutually exciting jump processes. Journal of Financial Economics $117(3), 585-606$.

Aït-Sahalia, Y., R. J. Laeven, and L. Pelizzon (2014). Mutual excitation in eurozone sovereign CDS. Journal of Econometrics 183(2), 151-167.

Almgren, R. (2012). High-frequency event analysis in eurex interest rate futures. Technical report, Working Paper, Quantitative Brokers.

Bacry, E., I. Mastromatteo, and J.-F. Muzy (2015). Hawkes processes in finance. Market Microstructure and Liquidity 1(01), 1550005.

Bai, J., C. Julliard, and K. Yuan (2012). Eurozone sovereign bond crisis: Liquidity or fundamental contagion. Federal Reserve Bank of New York Working Paper.

Banti, C., K. Phylaktis, and L. Sarno (2012). Global liquidity risk in the foreign exchange market. Journal of International Money and Finance 31(2), 267-291.

Beber, A., M. W. Brandt, and K. A. Kavajecz (2009). Flight-to-quality or flightto-liquidity? evidence from the euro-area bond market. Review of Financial Studies 22(3), 925-957.

Beber, A. and M. Pagano (2008). Measuring liquidity in the TLX market. mimeo.

Bormetti, G., L. M. Calcagnile, M. Treccani, F. Corsi, S. Marmi, and F. Lillo (2015). Modelling systemic price cojumps with Hawkes factor models. Quantitative Finance 15(7), 1137-1156.

Brockman, P., D. Y. Chung, and C. Pérignon (2009). Commonality in liquidity: A global perspective. Journal of Financial and Quantitative Analysis 44(04), 851-882.

Brunnermeier, M. K. and L. H. Pedersen (2009). Market liquidity and funding liquidity. Review of Financial Studies 22(6), 2201-2238.

Caporale, G. M. and A. Girardi (2011). Price formation on the EuroMTS platform. Applied Economics Letters 18(3), 229-233.

Caporale, G. M. and A. Girardi (2013). Price discovery and trade fragmentation in a multi-market environment: Evidence from the MTS system. Journal of Banking E Finance 37(2), 227-240.

Chakravarty, S. and A. Sarkar (1999). Liquidity in US fixed income markets: A comparison of the bid-ask spread in corporate, government and municipal bond markets. FRB of New York Staff Report (73). 
Cheung, Y. C., B. Rindi, and F. De Jong (2005). Trading European sovereign bonds: the microstructure of the MTS trading platforms. ECB working paper.

Chordia, T., R. Roll, and A. Subrahmanyam (2000). Commonality in liquidity. Journal of Financial Economics 56(1), 3-28.

Chordia, T., A. Sarkar, and A. Subrahmanyam (2005). An empirical analysis of stock and bond market liquidity. Review of Financial Studies 18(1), 85-129.

Claeys, G., Á. Leandro, and A. Mandra (2015). European central bank quantitative easing: the detailed manual. Bruegel Policy Contribution 2.

Coluzzi, C., S. Ginebri, and M. Turco (2008). Measuring and analyzing the liquidity of the Italian treasury security wholesale secondary market. Working paper, University of Molise.

Coughenour, J. F. and M. M. Saad (2004). Common market makers and commonality in liquidity. Journal of Financial Economics 73(1), 37-69.

Crosignani, M., M. Faria-e Castro, and L. Fonseca (2015). The (unintended?) consequences of the largest liquidity injection ever. NYU working paper.

Darbha, M. and A. Dufour (2013a). Measuring euro area government bond market liquidity and its asset pricing implications. Available at SSRN 2470944.

Darbha, M. and A. Dufour (2013b). Microstructure of the Euro-area government bond market. Market Microstructure in Emerging and Developed Markets: Price Discovery, Information Flows, and Transaction Costs, 39-58.

Dick-Nielsen, J., P. Feldhütter, and D. Lando (2012). Corporate bond liquidity before and after the onset of the subprime crisis. Journal of Financial Economics 103(3), 471-492.

Diebold, F. X. and K. Yllmaz (2014). On the network topology of variance decompositions: Measuring the connectedness of financial firms. Journal of Econometrics 182(1), 119-134.

Dufour, A. and M. Nguyen (2012). Permanent trading impacts and bond yields. The European Journal of Finance 18(9), 841-864.

Dufour, A., F. Skinner, et al. (2004). MTS time series: Market and data description for the European bond and repo database. Technical report, Henley Business School, Reading University.

Dumitru, A.-M. and G. Urga (2012). Identifying jumps in financial assets: A comparison between nonparametric jump tests. Journal of Business $\&$ Economic Statistics 30(2), 242-255.

Dunne, P., M. Moore, and R. Portes (2006). European government bond markets: Transparency, liquidity, efficiency. CEPR Research Report, London, UK. 
Dunne, P., M. J. Moore, R. Portes, et al. (2006). An empirical analysis of transparency-related characteristics of European and US sovereign bond markets. Technical report, Central Bank of Ireland.

Dunne, P. G., H. Hau, and M. Moore (2010). A tale of two platforms: dealer intermediation in the European sovereign bond market. INSEAD working paper.

Elyasiani, E., A. E. Kocagil, and I. Mansur (2007). Information transmission and spillover in currency markets: A generalized variance decomposition analysis. The Quarterly Review of Economics and Finance 47(2), 312-330.

Engle, R. (2002). New frontiers for ARCH models. Journal of Applied Econometrics $17(5), 425-446$.

Engle, R. F., M. J. Fleming, E. Ghysels, and G. Nguyen (2012). Liquidity, volatility, and flights to safety in the US treasury market: Evidence from a new class of dynamic order book models. FRB of New York Staff Report (590), 2013-20.

Fleming, M. J. (2003). Measuring treasury market liquidity. Economic policy review $9(3)$.

Fleming, M. J. and E. M. Remolona (1999). Price formation and liquidity in the US treasury market: The response to public information. The journal of Finance 54(5), 1901-1915.

Friewald, N., R. Jankowitsch, and M. G. Subrahmanyam (2012). Illiquidity or credit deterioration: A study of liquidity in the US corporate bond market during financial crises. Journal of Financial Economics 105(1), 18-36.

Ghysels, E., J. Idier, S. Manganelli, and O. Vergote (2014). A high frequency assessment of the ECB Securities Markets Programme. ECB Working Paper.

Golub, A., J. Keane, and S.-H. Poon (2012). High frequency trading and mini flash crashes. arXiv preprint arXiv:1211.6667.

Goyenko, R., A. Subrahmanyam, A. Ukhov, et al. (2011). The term structure of bond market liquidity and its implications for expected bond returns. Journal of Financial and Quantitative Analysis 46(1), 111.

Goyenko, R. Y., C. W. Holden, and C. A. Trzcinka (2009). Do liquidity measures measure liquidity? Journal of financial Economics 92(2), 153-181.

Hameed, A., W. Kang, and S. Viswanathan (2010). Stock market declines and liquidity. The Journal of Finance 65(1), 257-293.

Hasbrouck, J. and D. J. Seppi (2001). Common factors in prices, order flows, and liquidity. Journal of financial Economics 59(3), 383-411.

Hawkes, A. G. (1971a). Point spectra of some mutually exciting point processes. Journal of the Royal Statistical Society. Series B (Methodological), 438-443.

Hawkes, A. G. (1971b). Spectra of some self-exciting and mutually exciting point processes. Biometrika 58(1), 83-90. 
Huberman, G. and D. Halka (2001). Systematic liquidity. Journal of Financial Research 24(2), 161-178.

Johnson, N., G. Zhao, E. Hunsader, H. Qi, N. Johnson, J. Meng, and B. Tivnan (2013). Abrupt rise of new machine ecology beyond human response time. Scientific reports 3.

Kamara, A., X. Lou, and R. Sadka (2008). The divergence of liquidity commonality in the cross-section of stocks. Journal of Financial Economics 89(3), 444-466.

Karolyi, G. A., K.-H. Lee, and M. A. Van Dijk (2012). Understanding commonality in liquidity around the world. Journal of Financial Economics 105(1), 82-112.

Koch, A., S. Ruenzi, and L. T. Starks (2009). Commonality in liquidity: a demandside explanation. In AFA 2010 Atlanta Meetings Paper.

Koop, G., M. H. Pesaran, and S. M. Potter (1996). Impulse response analysis in nonlinear multivariate models. Journal of Econometrics 74(1), 119-147.

Krause, T. A., S. Ehsani, and D. D. Lien (2013). Exchange traded funds, liquidity, and market volatility. In Midwest Finance Association 2013 Annual Meeting Paper.

Lee, K.-H. (2011). The world price of liquidity risk. Journal of Financial Economics 99(1), 136-161.

Linciano, N., F. Fancello, M. Gentile, and M. Modena (2014). The liquidity of dual-listed corporate bonds. Empirical evidence from Italian markets. CONSOB Working Paper.

Lütkepohl, H. (1991). Introduction to Multiple Time Series Analysis. Springer.

Mancini, L., A. Ranaldo, and J. Wrampelmeyer (2013). Liquidity in the foreign exchange market: Measurement, commonality, and risk premiums. The Journal of Finance 68(5), 1805-1841.

Marshall, B. R., N. H. Nguyen, and N. Visaltanachoti (2013). Liquidity commonality in commodities. Journal of Banking \& Finance 37(1), 11-20.

Ogata, Y. (1988). Statistical models for earthquake occurrences and residual analysis for point processes. Journal of the American Statistical association 83(401), $9-27$.

Papapetrou, E. (2001). Oil price shocks, stock market, economic activity and employment in Greece. Energy Economics 23(5), 511-532.

Pasquariello, P. and C. Vega (2007). Informed and strategic order flow in the bond markets. Review of Financial Studies 20(6), 1975-2019.

Pasquariello, P. and C. Vega (2012). Government intervention and strategic trading in the US treasury market. Available at SSRN 1769773. 
Pelizzon, L., M. Subrahmanyam, D. Tomio, and J. Uno (2014). Limits to arbitrage in sovereign bonds price and liquidity discovery in high frequency quote driven markets. Mimeo.

Pelizzon, L., M. G. Subrahmanyam, D. Tomio, and J. Uno (2015). Sovereign credit risk, liquidity, and ECB intervention: Deus ex machina? Journal of Financial Economics, forthcoming.

Pesaran, H. H. and Y. Shin (1998). Generalized impulse response analysis in linear multivariate models. Economics letters 58(1), 17-29.

Schwert, M. (2009). Hop, skip and jump - what are modern 'jump' tests finding in stock returns? Available at SSRN 1648986.

Sims, C. A. (1980). Macroeconomics and reality. Econometrica: Journal of the Econometric Society, 1-48.

Theodosiou, M. G. and F. Zikes (2011). A comprehensive comparison of nonparametric tests for jumps in asset prices. Available at SSRN 1895364.

Vere-Jones, D. (1970). Stochastic models for earthquake occurrence. Journal of the Royal Statistical Society. Series B (Methodological), 1-62.

Vere-Jones, D. (1995). Forecasting earthquakes and earthquake risk. International Journal of Forecasting 11(4), 503-538. 


\section{A List of ISINs}

\begin{tabular}{cc|c|c|c|}
\cline { 3 - 5 } & 3 & $2011 / 12$ & 2013 & $2014 / 15$ \\
\hline \multirow{2}{*}{5 year BTP } & 2 & IT0004615917 & IT0004793474 & IT0004957574 \\
& 1 & IT0004656275 & IT0004820426 & IT0004992308 \\
\hline \multirow{2}{*}{10 year BTP } & 3 & IT0004594930 & IT0004801541 & IT0004953417 \\
& 2 & IT0004634132 & IT0004848831 & IT0005001547 \\
& 1 & IT0004695075 & IT0004898034 & IT0005045270 \\
\hline \multirow{3}{*}{30 year BTP } & 3 & IT0003934657 & IT0003934657 & IT0004286966 \\
& 2 & IT0004286966 & IT0004286966 & IT0004532559 \\
& 1 & IT0004532559 & IT0004532559 & IT0004923998 \\
\hline
\end{tabular}

Table 3: List of bonds used in each subperiod. For each subperiod we include the three most recently issued 5, 10 and 30 year Italian BTPs that are actively traded during the whole subperiod. Bonds are ordered in increasing time-to-maturity, e.g. the bond denoted "5 year 1" is the most recently issed 5y BTP in the (whole) subperiod.

Table 3 gives the ISINs of the bonds that we use for our analysis. For each subperiod we include the three most recently issued 5, 10 and 30 year fixed-rate Italian government bonds (Buoni del Tesoro Poliennale, BTP) that are actively traded during the whole subperiod. While 5 and 10 year BTPs are frequently issued and thus change from subperiod to subperiod, there is only one new 30 year BTP in the $2014 / 15$ period.

\section{B Computation of PCA1}

To obtain a condensed measure of illiquidity we perform a principal component analysis (PCA) for each bond on the "raw" measures spread, inverse depth and total quoted volume as in Mancini et al. (2013) and Fleming (2003). Let $\boldsymbol{L}$ be the $T \times 3$ matrix of the demeaned and standardized time-series ( $T$ observations) of the three liquidity metrics above, then the empirical covariance matrix is proportional to $\boldsymbol{L}^{\prime} \boldsymbol{L}=\boldsymbol{V} \boldsymbol{\Lambda} \boldsymbol{V}^{\prime}$ where $\boldsymbol{\Lambda}$ is the $3 \times 3$ diagonal matrix of eigenvalues and $\boldsymbol{V}$ the $3 \times 3$ matrix of eigenvectors of $\boldsymbol{L}^{\prime} \boldsymbol{L} .{ }^{51}$

The eigenvector corresponding to the first principal component, capturing the majority of variance in liquidity, has positive eigenvector loadings in the Spread and Inverse Depth component and negative loading in the Total Volume component, thus measuring illiquidity. ${ }^{52}$ We construct the time-series of our condensed illiquidity measure $P C A 1$ as $P C A 1=\boldsymbol{L} \boldsymbol{v}_{1}$ and therefore we can obtain $P C A 1$ at the same millisecond or higher time-resolution as our data.

\footnotetext{
${ }^{51}$ The $i$ th column of $\boldsymbol{V}$ is the $i$ th eigenvector and denoted $\boldsymbol{v}_{i}$.

${ }^{52}$ The eigenvector is uniquely defined up to a sign. We decide to normalize the Spread component to always be positive, i.e. to measure illiquidity as opposed to liquidity. We calculate the PCA for each bond and sub-period from the concatenated time-series of intraday liquidity sampled at one-minute intervals from 9:30 to 17:15. Eigenvectors are similar both across bonds and periods and robust to different sampling frequencies.
} 


\section{Commonality of Liquidity}

Tables 4 to 6 show the average intraday correlation matrix of liquidity (PCA1) for each of our subperiods respectively. That is, for each day we sample PCA1 at oneminute intervals between 9:30 and 17:15, remove the intraday pattern of liquidity and compute the correlation matrix of PCA1 for that day. The average intraday correlation matrix is the mean over all days in the subperiod, where days with invalid observations are discarded..$^{53}$

\begin{tabular}{cc||ccc|ccc|ccc|}
\multicolumn{1}{l||}{} & \multicolumn{3}{c|}{30 year BTP } & \multicolumn{3}{c|}{10} & year BTP & \multicolumn{3}{c|}{5 year BTP } \\
& & 1 & 2 & 3 & 1 & 2 & 3 & 1 & 2 & 3 \\
\hline \hline \multirow{3}{*}{30 year BTP } & 1 & 1.00 & 0.83 & 0.78 & 0.46 & 0.49 & 0.47 & 0.43 & 0.44 & 0.43 \\
& 2 & 0.83 & 1.00 & 0.80 & 0.46 & 0.48 & 0.47 & 0.42 & 0.43 & 0.43 \\
& 3 & 0.78 & 0.80 & 1.00 & 0.45 & 0.47 & 0.46 & 0.42 & 0.43 & 0.42 \\
\hline \multirow{3}{*}{ 10 year BTP } & 1 & 0.46 & 0.46 & 0.45 & 1.00 & 0.72 & 0.71 & 0.57 & 0.58 & 0.56 \\
& 2 & 0.49 & 0.48 & 0.47 & 0.72 & 1.00 & 0.77 & 0.59 & 0.60 & 0.58 \\
& 3 & 0.47 & 0.47 & 0.46 & 0.71 & 0.77 & 1.00 & 0.59 & 0.60 & 0.58 \\
\hline \multirow{3}{*}{5 year BTP } & 1 & 0.43 & 0.42 & 0.42 & 0.57 & 0.59 & 0.59 & 1.00 & 0.76 & 0.73 \\
& 2 & 0.44 & 0.43 & 0.43 & 0.58 & 0.60 & 0.60 & 0.76 & 1.00 & 0.76 \\
& 3 & 0.43 & 0.43 & 0.42 & 0.56 & 0.58 & 0.58 & 0.73 & 0.76 & 1.00 \\
\hline
\end{tabular}

Table 4: Average correlation matrix of liquidity (PCA1). Mean over daily correlation matrices from intraday time series from June 2011 through February 2012. Time-series were sampled at one-minute intervals and the intraday pattern removed in the underlying liquidity metrics. Days with invalid observations were discarded.

Table 4 shows the average intraday correlation matrix of liquidity (PCA1) for the period June 2011 through February 2012. The matrix shows a block-structure, i.e. correlation is roughly the same for pairs of bonds with similar maturities. Average correlation is larger than 0.4 even for pairs with the highest difference in maturity ( 5 and 30 year BTPs) and the strongest on the diagonal blocks: larger than 0.7 within the 5 and 10 year BTPs and around 0.8 for the 30 year BTPs.

The average intraday correlation during the period March 2013 through December 2013 in Table 5 shows the same structure as the 2011 period. Correlations on the diagonal block are somewhat lower than in 2011 and similar in the off-diagonals.

Table 6 shows the average intraday correlation matrix of liquidity (PCA1) in the period October 2014 through June 2015, with the same block-structure. Average correlation is ca. 0.5 for pairs with the highest difference in maturity and as high as 0.9 on the diagonal block for the 30 year BTPs.

We observe that correlation and commonality of liquidity in the sovereign bond market has increased even compared to the peak of the sovereign bond crisis.

\footnotetext{
${ }^{53}$ Results are similar when the intraday pattern of liquidity is not removed.
} 


\begin{tabular}{cc||ccc|ccc|ccc|}
\multicolumn{1}{l||}{} & \multicolumn{3}{c||}{30 year BTP } & \multicolumn{3}{c|}{ 10 year BTP } & \multicolumn{3}{c}{5 year BTP } \\
& & 1 & 2 & 3 & 1 & 2 & 3 & 1 & 2 & 3 \\
\hline \hline \multirow{3}{*}{30 year BTP } & 1 & 1.00 & 0.79 & 0.62 & 0.51 & 0.52 & 0.53 & 0.48 & 0.45 & 0.47 \\
& 2 & 0.79 & 1.00 & 0.61 & 0.49 & 0.50 & 0.51 & 0.46 & 0.43 & 0.44 \\
& 3 & 0.62 & 0.61 & 1.00 & 0.38 & 0.40 & 0.39 & 0.35 & 0.33 & 0.34 \\
\hline \multirow{3}{*}{10 year BTP } & 1 & 0.51 & 0.49 & 0.38 & 1.00 & 0.61 & 0.63 & 0.54 & 0.51 & 0.52 \\
& 2 & 0.52 & 0.50 & 0.40 & 0.61 & 1.00 & 0.65 & 0.53 & 0.50 & 0.51 \\
& 3 & 0.53 & 0.51 & 0.39 & 0.63 & 0.65 & 1.00 & 0.55 & 0.53 & 0.53 \\
\hline \multirow{3}{*}{5 year BTP } & 1 & 0.48 & 0.46 & 0.35 & 0.54 & 0.53 & 0.55 & 1.00 & 0.70 & 0.72 \\
& 2 & 0.45 & 0.43 & 0.33 & 0.51 & 0.50 & 0.53 & 0.70 & 1.00 & 0.70 \\
& 3 & 0.47 & 0.44 & 0.34 & 0.52 & 0.51 & 0.53 & 0.72 & 0.70 & 1.00 \\
\hline
\end{tabular}

Table 5: Average correlation matrix of liquidity (PCA1). Mean over daily correlation matrices from intraday time series from March 2013 through December 2013. Time-series were sampled at one-minute intervals and the intraday pattern removed in the underlying liquidity metrics. Days with invalid observations were discarded.

\begin{tabular}{cc||ccc|ccc|ccc|}
\multicolumn{1}{l||}{} & \multicolumn{3}{c||}{30 year BTP } & \multicolumn{3}{c|}{ 10 year BTP } & \multicolumn{3}{c}{5 year BTP } \\
& & 1 & 2 & 3 & 1 & 2 & 3 & 1 & 2 & 3 \\
\hline \hline \multirow{3}{*}{30 year BTP } & 1 & 1.00 & 0.90 & 0.91 & 0.59 & 0.61 & 0.61 & 0.49 & 0.49 & 0.51 \\
& 2 & 0.90 & 1.00 & 0.92 & 0.60 & 0.61 & 0.61 & 0.49 & 0.49 & 0.51 \\
& 3 & 0.91 & 0.92 & 1.00 & 0.60 & 0.61 & 0.61 & 0.49 & 0.49 & 0.51 \\
\hline \multirow{3}{*}{10 year BTP } & 1 & 0.59 & 0.60 & 0.60 & 1.00 & 0.80 & 0.78 & 0.55 & 0.54 & 0.57 \\
& 2 & 0.61 & 0.61 & 0.61 & 0.80 & 1.00 & 0.83 & 0.57 & 0.57 & 0.58 \\
& 3 & 0.61 & 0.61 & 0.61 & 0.78 & 0.83 & 1.00 & 0.57 & 0.56 & 0.58 \\
\hline \multirow{3}{*}{5 year BTP } & 1 & 0.49 & 0.49 & 0.49 & 0.55 & 0.57 & 0.57 & 1.00 & 0.73 & 0.74 \\
& 2 & 0.49 & 0.49 & 0.49 & 0.54 & 0.57 & 0.56 & 0.73 & 1.00 & 0.73 \\
& 3 & 0.51 & 0.51 & 0.51 & 0.57 & 0.58 & 0.58 & 0.74 & 0.73 & 1.00 \\
\hline
\end{tabular}

Table 6: Average correlation matrix of liquidity (PCA1). Mean over daily correlation matrices from intraday time series from October 2014 through June 2015. Time-series were sampled at one-minute intervals and the intraday pattern removed in the raw liquidity metrics. Days with invalid observations were discarded.

\section{Generalized Variance Decomposition}

\section{D.1 Diagonal component of Generalized Variance Decom- position}

Figure 9 shows the average generalized variance decomposition for a forecast horizon of 10 minutes $(H=10)$, showing only the elements where variation and shock occurred in the same asset. The diagonal elements, i.e. the liquidity variation in one asset as a reaction to shocks in the same asset, are typically explained to $80-90 \%$, generally a higher value than the cross-asset values reported in Section 5. 


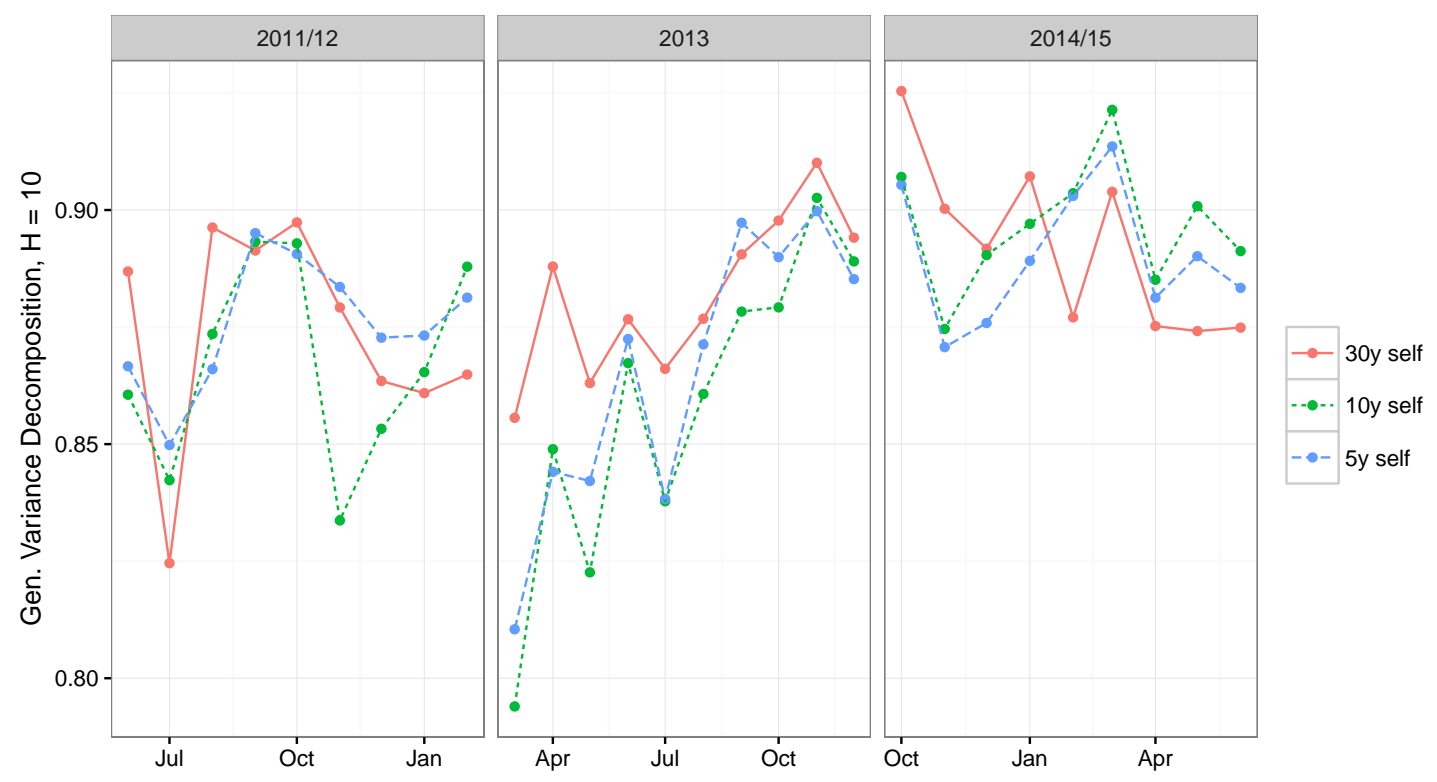

Figure 9: Average Generalized Variance Decomposition for a forecast horizon of 10 minutes $(H=10)$, same-asset components. Mean of daily estimations per month and maturity grouping. Time-series sampled at one-minute intervals without removal of the intraday pattern. Days with invalid observations were discarded. The label "30y self" refers to the variation in 30 year BTPs caused by shocks to the same 30 year BTP.

\section{D.2 Normalized Generalized Variance Decomposition}

A downside of the generalized variance decomposition is that the contributions from different shocks are no longer normalized as for the case of orthogonal shocks. Diebold and Yilmaz (2014) therefore choose to row-normalize the components of $d_{i j}(H)$ such that each row sums to 1 , i.e. $\tilde{d}_{i j}(H)=\frac{d_{i j}(H)}{\sum_{j=1}^{N} d_{i j}(H)}$. For robustness we also show the corresponding result in Figure 10. We do observe the same band structure as described above. Since rows are normalized what we observed as dips in August and November/December 2011 in Figure 5 now manifests as peaks of the autoregressive component (e.g. "30y self").

\section{D.3 Generalized Variance Decomposition with independent shocks}

In the generalized variance decomposition a high share of variation is explained by the effect of shocks in other bonds because of the strong correlation of these shocks. Here we replace $\boldsymbol{\Sigma}$ in equation (4) with its diagonal, setting the off-diagonal elements of $\Sigma$ to 0 , with all other parameters equal.

As we can see in Figure 11 the corresponding values of $d_{i j}(10), i \neq j$ descend to approximately $10 \%$ and the band structure vanishes. We thus deduce that the correlation in the idiosyncratic term is the main driver of commonality in liquidity and the band structure that we observe in Section 5. This implies that the majority of the dynamics of liquidity happens at time-scales much shorter than our sampling 

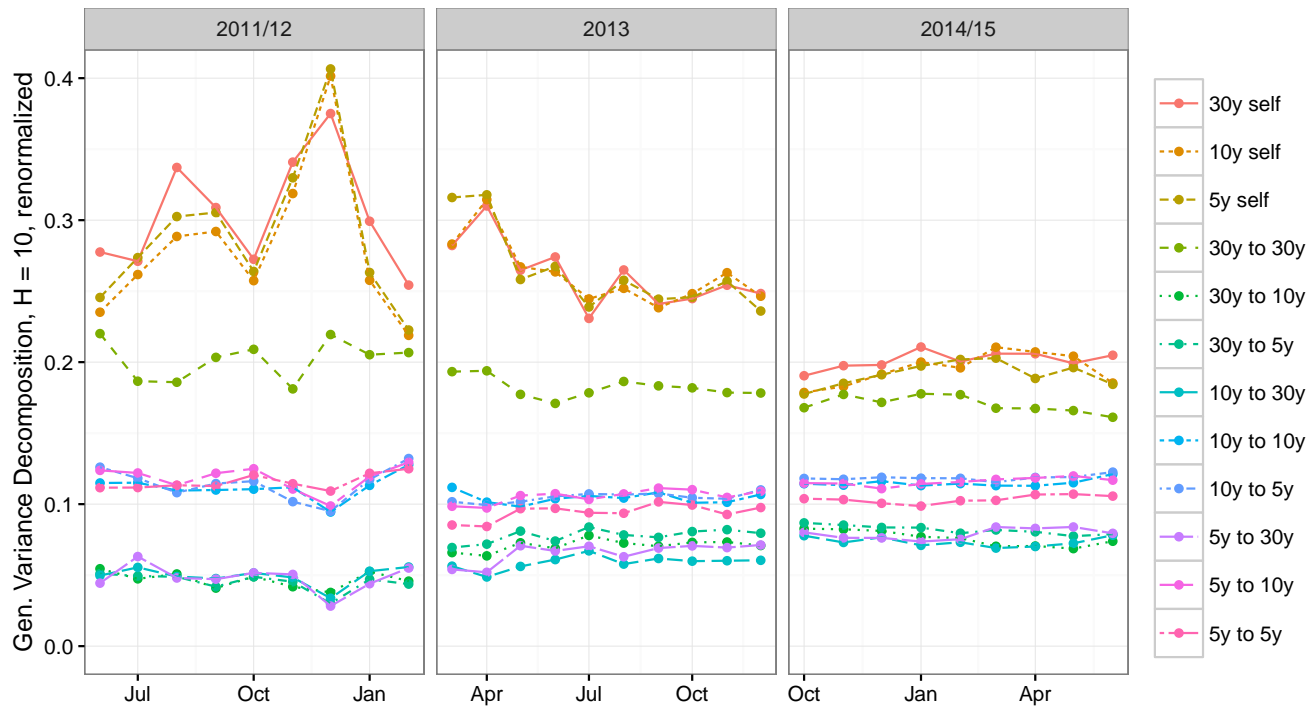

Figure 10: Average Generalized Variance Decomposition for a forecast horizon of 10 minutes $(H=10)$, using the row-normalization of Diebold and Yllmaz (2014). Mean of daily estimations per month and maturity grouping. Time-series sampled at one-minute intervals without removal of the intraday pattern. Days with invalid observations were discarded. The label "30y self" refers to the autoregressive component in the liquidity of 30 year BTPs while the label "5y to 30y" refers to the variation in 30 year BTPs caused by shocks to 5 year BTPs.
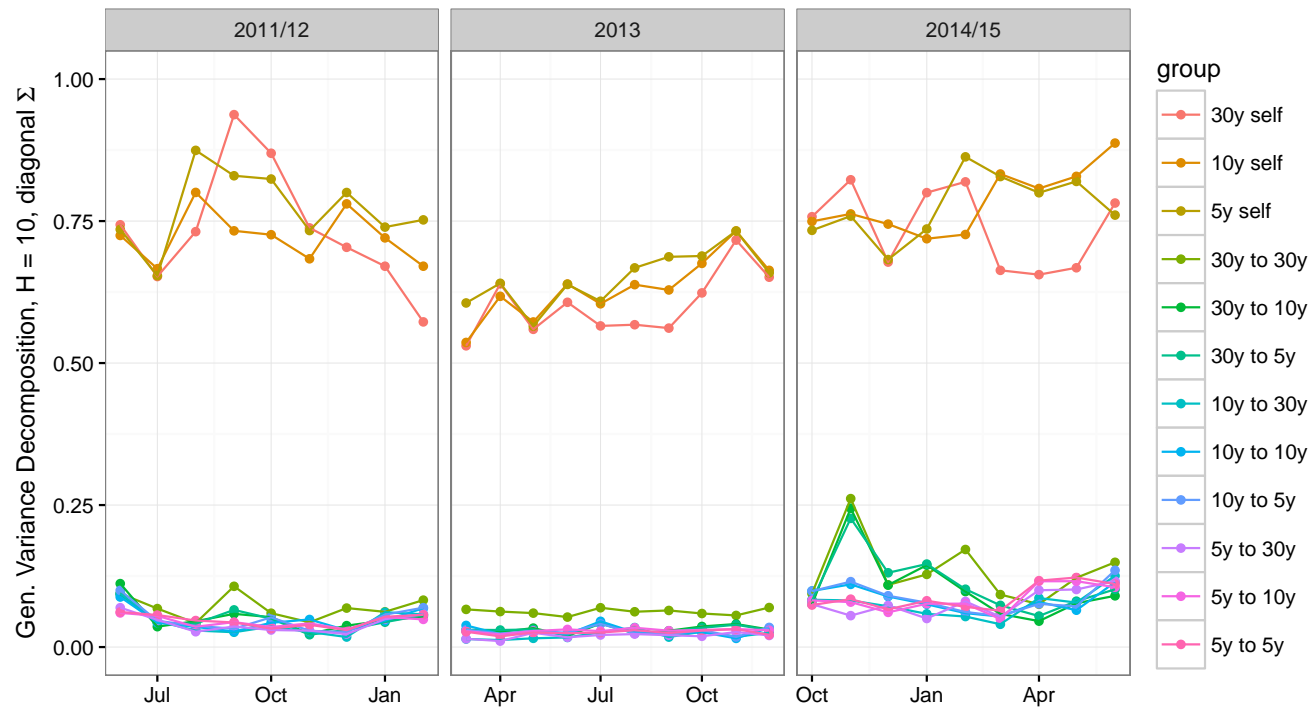

Figure 11: Average Generalized Variance Decomposition for a forecast horizon of 10 minutes $(H=10)$, using uncorrelated shocks, i.e. replacing $\Sigma$ in equation (4) with its diagonal. Mean of daily estimations per month and maturity grouping. Timeseries sampled at one-minute intervals without removal of the intraday pattern. Days with invalid observations were discarded. The label "30y self" refers to the autoregressive component in the liquidity of 30 year BTPs while the label "5y to $30 y "$ refers to the variation in 30 year BTPs caused by shocks to 5 year BTPs. 


\section{E Snapshots of the Limit Order Book}

\section{E.1 Dry-Up of Market Liquidity}

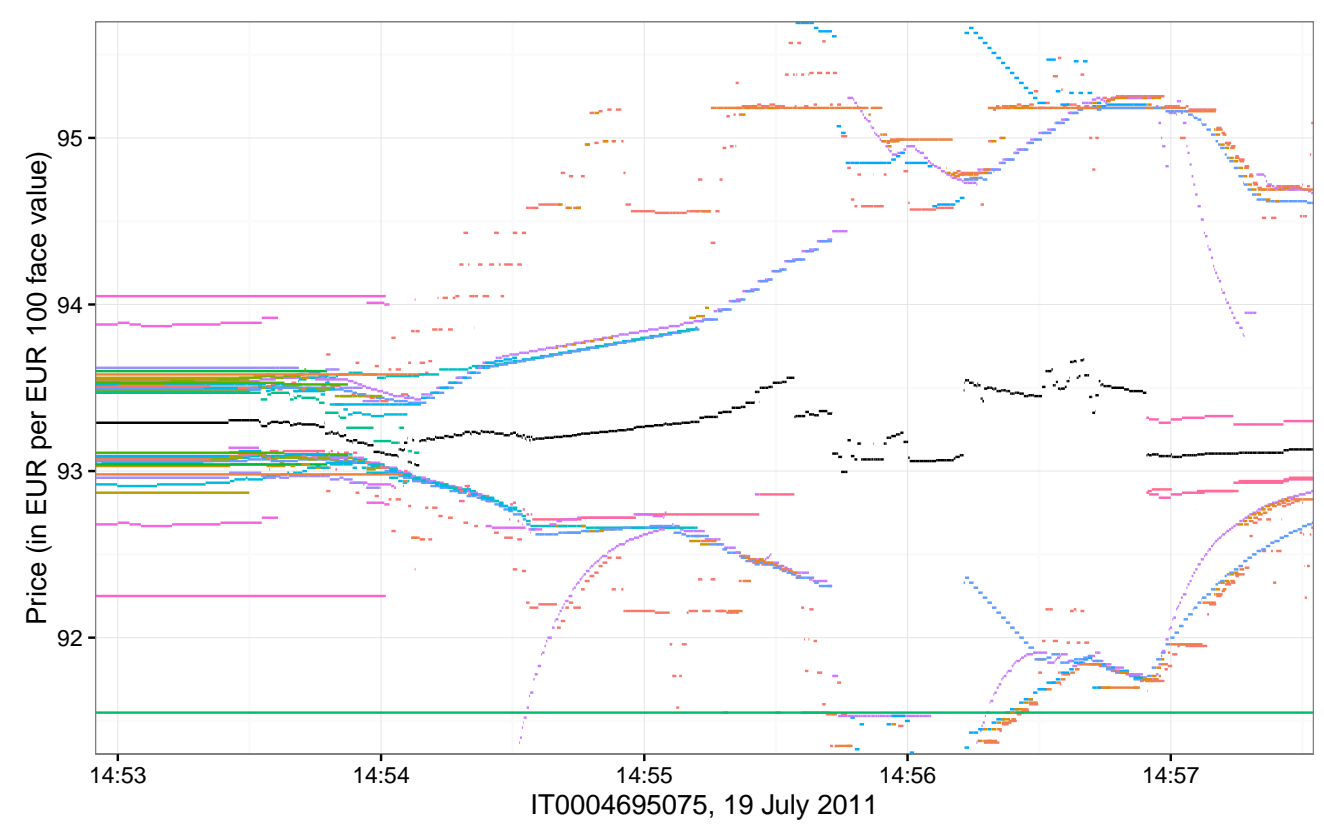

Figure 12: Limit Order Book snapshot with an example of liquidity drying up. Colored horizontal lines correspond to different quotes, each color corresponding to a quote from a different participant. The mid price (black horizontail lines) separates the bid and ask side. No trades in this bond were reported during the period displayed.

Figure 12 shows as an example a snapshot of the limit order book of the 10 year on-the-run BTP from 19 July 2011 where the spread widens considerably and most participants retreat from participating in the market. ${ }^{54}$ At 14:53 spread is reasonably small ${ }^{55}$ and both sides of the order book are densely populated with quotes, most of them within a few ticks of the best. From around 14:53:30 the order book thins out and participants retreat, while the spread initially gets smaller due to single quotes lowering the ask price (thus increasing inverse depth). Shortly after 14:54 only a handful of participants are left quoting and the bid-ask spread widens to more than 300 basis points. Spread eventually returns to more normal values at 14:57 but the depth of the limit order book remains stricken.

First, we observe that one liquidity metric by itself is not enough to capture the dynamics. Spread initially becomes smaller while many participants suspend their

\footnotetext{
${ }^{54}$ We are not aware of any news announcements at that time, however Italian markets were clearly in distress about hitting the $6 \%$ yield threshold.

${ }^{55}$ I.e. within the average of the period considered, ca. 50 basis points corresponding to $€ 0.5$ (per $€ 100$ face value) for the 10 year BTP in $2011 / 12$, c.f. Table 1
} 
quotes, thus decreasing the total quoted volume. Therefore we use only PCA1 in this section as it captures all these aspects of liquidity.

Second, Figure 12 reveals that liquidity does not "jump" if looking at different metrics combined (and at sufficiently high observation frequency), but rather "rushes" towards illiquidity in a succession of small but fast steps. This is sensible since from the microscopic point of view liquidity is composed of the quotes from a set of market participants. In fact we observe that there is a grouping of participants into some that are "confident" in posting their quotes whereas the larger part is merely "following" by e.g. pegging their orders one tick size behind the best or posting very conservative quotes. ${ }^{56}$

\section{E.2 Illiquidity events detected}

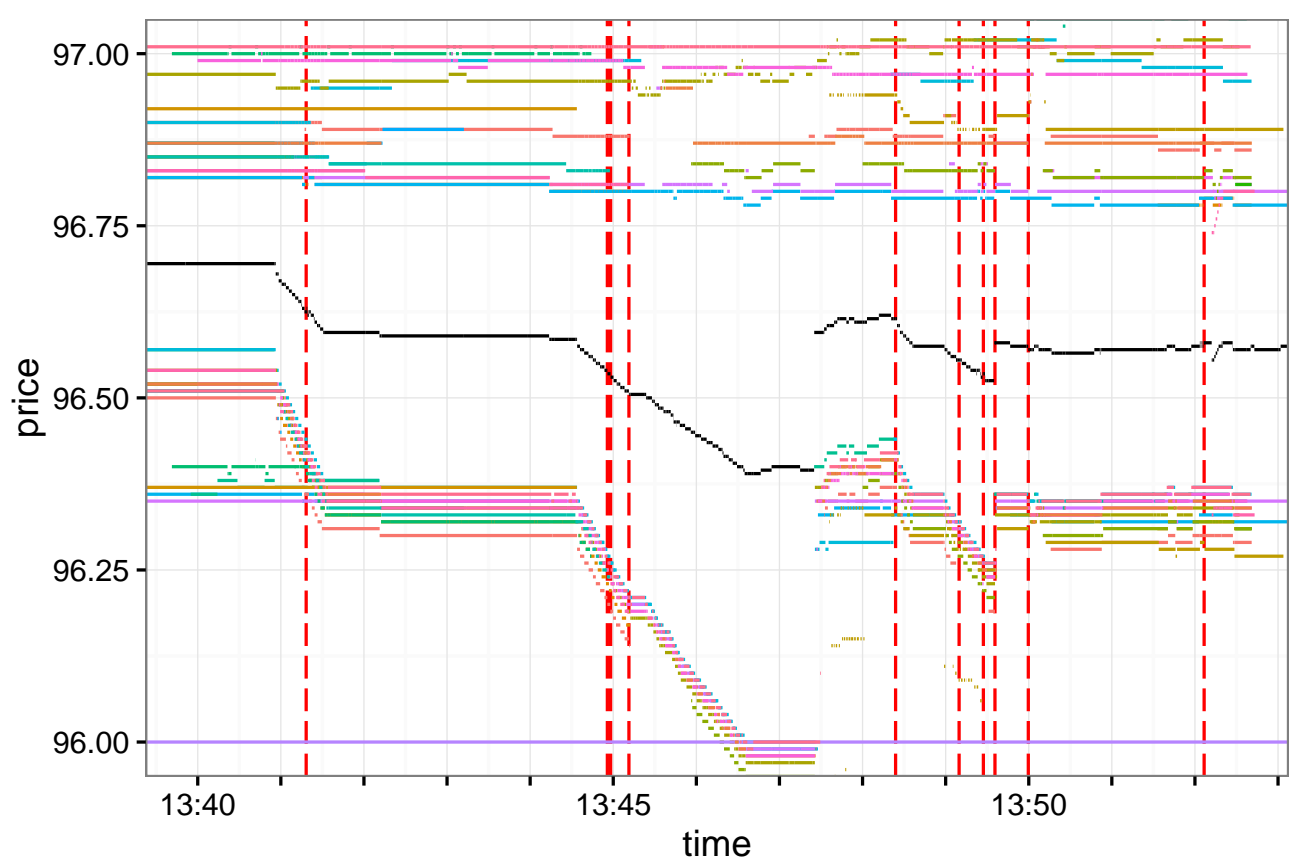

Figure 13: Limit Order Book snapshot with detected illiquidity events (dashed vertical red lines). Colored horizontal lines correspond to different quotes, each color corresponding to a quote from a different participant. The mid price (black horizontail lines) separates the bid and ask side. No trades in this bond were reported during the period displayed.

Figure 13 shows an excerpt of the limit order book where the detected illiquidity events are marked by the dashed vertical red lines. Note that an event does not necessarily correspond to a widening of the spread (e.g. the event at ca. 13:52) but could also be caused by the cancellation of proposals deeper in the LOB and the resulting deterioration of the total quoted volume or inverse depth. 


\begin{tabular}{|c|c|c|c|c|c|c|c|c|c|c|c|}
\hline & \multirow{2}{*}{ all } & \multicolumn{3}{|c|}{5 year BTP } & \multicolumn{3}{|c|}{10 year BTP } & \multicolumn{3}{|c|}{30 year BTP } \\
\hline & & & 3 & 2 & 1 & 3 & 2 & 1 & 3 & 2 & 1 \\
\hline \multirow{4}{*}{$2011 / 12$} & $10 \% \mathrm{Q}$ & 25.0 & 20.0 & 22.0 & 23.4 & 28.0 & 25.0 & 29.4 & 28.4 & 28.4 & 26.0 \\
\hline & mean & 101.3 & 96.3 & 88.2 & 88.8 & 104.9 & 101.3 & 111.0 & 106.3 & 101.3 & 113.3 \\
\hline & median & 69.0 & 57.0 & 56.0 & 61.0 & 72.0 & 71.0 & 87.0 & 81.0 & 74.0 & 78.0 \\
\hline & $90 \% \mathrm{Q}$ & 210.0 & 203.8 & 168.0 & 187.4 & 198.6 & 207.6 & 213.4 & 219.0 & 228.4 & 239.0 \\
\hline \multirow{4}{*}{2013} & $10 \% \mathrm{Q}$ & 35.0 & 38.0 & 33.0 & 35.0 & 31.0 & 31.0 & 41.0 & 28.0 & 38.0 & 35.0 \\
\hline & mean & 137.7 & 116.3 & 111.8 & 121.5 & 157.8 & 152.9 & 148.1 & 151.8 & 134.6 & 145.0 \\
\hline & median & 101.0 & 98.0 & 88.0 & 93.0 & 105.0 & 101.0 & 113.0 & 113.0 & 99.0 & 114.0 \\
\hline & $90 \% \mathrm{Q}$ & 295.0 & 216.0 & 225.0 & 250.0 & 341.0 & 375.0 & 318.0 & 329.0 & 295.0 & 299.0 \\
\hline \multirow{4}{*}{$2014 / 15$} & $10 \% \mathrm{Q}$ & 23.0 & 26.5 & 28.0 & 26.0 & 20.0 & 19.5 & 16.5 & 25.5 & 19.0 & 22.0 \\
\hline & mean & 116.3 & 89.8 & 109.7 & 95.8 & 121.8 & 123.2 & 125.6 & 114.5 & 132.2 & 134.0 \\
\hline & median & 66.0 & 62.0 & 71.5 & 70.0 & 67.0 & 61.0 & 60.0 & 74.0 & 62.5 & 60.0 \\
\hline & $90 \% \mathrm{Q}$ & 262.0 & 167.5 & 211.0 & 173.0 & 302.0 & 323.5 & 280.0 & 245.5 & 344.0 & 399.5 \\
\hline \multirow{4}{*}{ all } & $10 \% \mathrm{Q}$ & 26.0 & 26.0 & 26.0 & 26.1 & 26.0 & 25.0 & 26.0 & 27.1 & 26.0 & 25.0 \\
\hline & mean & 119.0 & 101.4 & 103.3 & 102.6 & 129.1 & 126.6 & 128.8 & 125.1 & 122.9 & 131.1 \\
\hline & median & 78.0 & 69.0 & 72.0 & 73.0 & 82.0 & 75.5 & 89.0 & 86.5 & 83.0 & 82.0 \\
\hline & $90 \% \mathrm{Q}$ & 254.0 & 199.0 & 206.9 & 205.7 & 293.9 & 307.7 & 267.0 & 282.1 & 268.7 & 278.9 \\
\hline
\end{tabular}

Table 7: Summary statistics of the number of illiquidity events detected per bond and day. 10\%Q and 90\%Q refer to the 10\% and 90\% percentile respectively. Bonds are ordered in increasing time-to-maturity, e.g. the bond denoted " 5 year 1 " is the most recently issed 5y BTP in the (complete) subperiod.

\section{F Statistics of Illiquidity events}

Table 7 displays the summary statistics of the number of illiquidity events detected per bond and day, broken down both by subperiod and bond. The mean number of illiquidity events per bond and day is 119.0 (in the $2011 / 12$ subperiod slightly lower with 101.3 and slightly higher in the 2013 period with 137.7) and the median is 78 (slightly lower in 2011/12 and 2014/15 with 69 and 66 events per bond and day respectively and higher in 2013 with 101 events per bond and day). Comparing across maturities, 5 year BTPs get a mean (median) of ca. 102 (71) illiquidity events per bond and day, whereas 10 and 30 year see a few more, ca. 128 (82) and 126 (84) respectively.

These differences can at least partially be explained considering the assumptions we made for the illiquidity event detection scheme. Concerning the differences across periods, the threshold is chosen as the $95 \%$ percentile of all velocities $\frac{P C A 1^{i}\left(t_{m}\right)-P C A 1^{i}\left(t_{m-l}\right)}{t_{m}-t_{m-l}}$ whereas for illiquidity events there is the restriction that two illiquidity events need to be at least $l$ limit-order-book updates apart. So if potential illiquidity events are happening shortly after each other, some of them will be discarded due to this restriction. This effect is the stronger the more potential illiquidity events are clustered in time and this explains why there are more illiquidity events in the rather calm 2013 period. Concerning the difference across maturities, in choosing $l$ as the average number of limit-order-book updates over a certain time frame, we had assumed that limit-order-book updates scale linearly. If however in the rather actively traded 5 year BTPs trading activity scales up less than for the less active 10 and 30 year BTPs, the effective $l$ is larger for the 5 year titles and

\footnotetext{
${ }^{56}$ This has been confirmed in conversations with market participants.
} 
using the same argument as above we would have less detected illiquidity events there.

Finally Table 7 hints that the distribution of jumps is skewed towards large values, which we confirm in Figure 14.

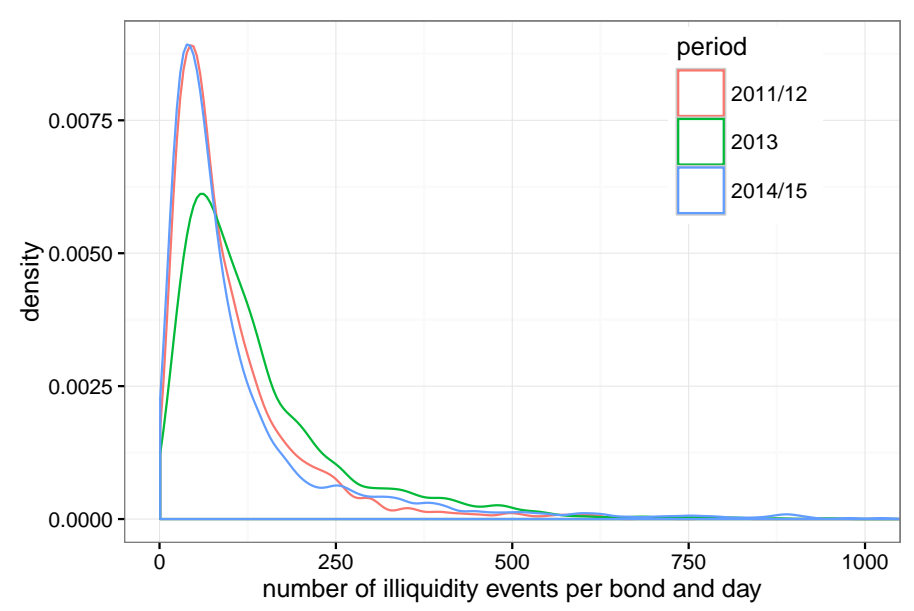

(a) by subperiod

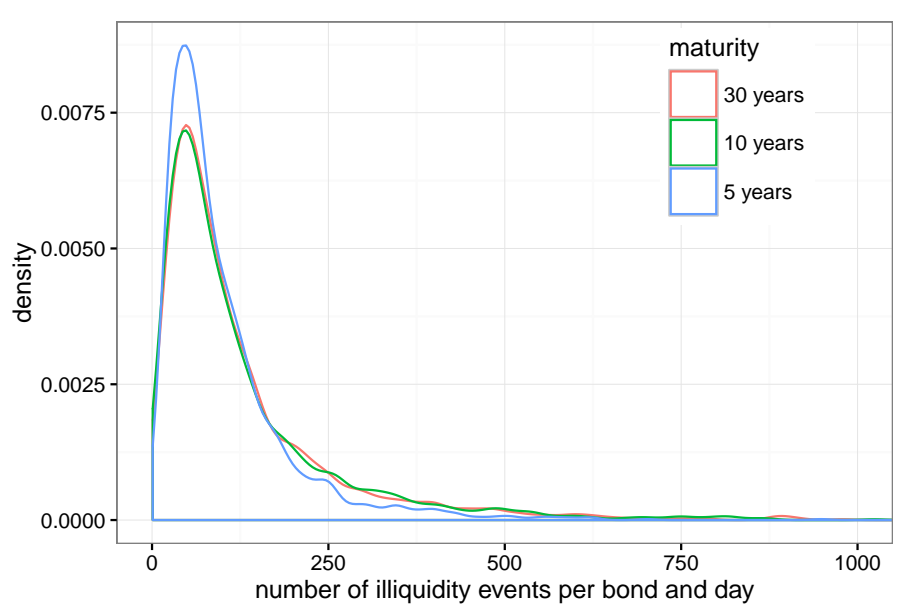

(b) by maturity

Figure 14: Density plot of the number of illiquidity events detected per bond and day, distinguished by subperiod (a) and maturity (b).

Figure 14 shows the density plot of the number of illiquidity events detected per bond and day, distinguished by subperiod (a) and maturity (b). As alluded above the distribution is skewed towards larger numbers of events. Beyond the somewhat higher number of events in 2013 mentioned abobe, the distribution is consistent across both periods and maturities. 


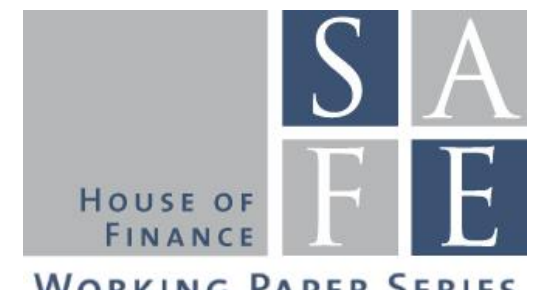

WORKING PAPER SERIES

\section{Recent Issues}

No.150 Vanya Horneff, Raimond Maurer, Olivia S. Mitchell

No. 149

Massimiliano Caporin, Aleksey

Kolokolov, Roberto Renò

No. 148 Sven-Thorsten Jakusch

No. 147 Andreas Hackethal, Sven-Thorsten Jakusch, Steffen Meyer

No.146 Sven-Thorsten Jakusch, Steffen Meyer, Andreas Hackethal

No. 145 Christian Geppert, Alexander Ludwig, Raphael Abiry

No. 144 Mario Bellia, Loriana Pelizzon, Marti G. Subrahmanyam, Jun Uno, Darya Yuferova

No. 143 Peter Gomber, Satchit Sagade, Erik Theissen, Moritz Christian Weber, Christian Westheide

No. 142 Nathanael Vellekoop

No. 141 Brigitte Haar

No. 140 Reint Gropp, Rasa Karapandza, Julian Opferkuch

No. 139 Holger Kraft, Claus Munk, Farina Weiss

No.138 Mohammed Aldegwy, Matthias Thiemann
Putting the Pension back in 401(k) Plans: Optimal versus Default Longevity Income Annuities

Systemic Co-Jumps

On the Applicability of Maximum Likelihood Methods: From Experimental to Financial Data

Taring all Investors with the same Brush? Evidence for Heterogeneity in Individual Preferences from a Maximum Likelihood Approach

Taming Models of Prospect Theory in the Wild? Estimation of Vlcek and Hens (2011)

Secular Stagnation? Growth, Asset Returns and Welfare in the Next Decades: First Results

Low-Latency Trading and Price Discovery: Evidence from the Tokyo Stock Exchange in the Pre-Opening and Opening Periods

Spoilt for Choice: Order Routing Decisions in Fragmented Equity Markets

The Impact of Long-Run Macroeconomic Experiences on Personality

Freedom of Contract and Financial Stability through the lens of the Legal Theory of Finance

The Forward-Looking Disclosures of Corporate Managers: Theory and Evidence

Predictors and Portfolios Over the Life Cycle

How Economics Got it Wrong: Formalism, Equilibrium Modelling and PseudoOptimization in Banking Regulatory Studies 